Article

\title{
Energetics of LOHC: Structure-Property Relationships from Network of Thermochemical Experiments and in Silico Methods
}

\author{
Sergey P. Verevkin ${ }^{1,2, * \mathbb{D}}$, Vladimir N. Emel'yanenko $^{2}$, Riko Siewert ${ }^{1}$ and Aleksey A. Pimerzin ${ }^{2}$ (D) \\ 1 Department of Physical Chemistry and Faculty of Interdisciplinary Research, Competence Centre CALOR, \\ University of Rostock, 18051 Rostock, Germany; riko.siewert@uni-rostock.de \\ 2 Chemical Department, Samara State Technical University, 443100 Samara, Russia; vladchimic@tut.by (V.N.E.); \\ aleksey@pimerzin.com (A.A.P.) \\ * Correspondence: sergey.verevkin@uni-rostock.de; Tel.: +49-381-498-6508; Fax: +49-381-498-6502
}

check for updates

Citation: Verevkin, S.P.;

Emel'yanenko, V.N.; Siewert, R.;

Pimerzin, A.A. Energetics of LOHC: Structure-Property Relationships from Network of Thermochemical Experiments and in Silico Methods. Hydrogen 2021, 2, 101-121.

https://doi.org/10.3390/

hydrogen 2010006

Received: 3 December 2020

Accepted: 3 February 2021

Published: 9 February 2021

Publisher's Note: MDPI stays neutral with regard to jurisdictional claims in published maps and institutional affiliations.

Copyright: (c) 2021 by the authors. Licensee MDPI, Basel, Switzerland. This article is an open access article distributed under the terms and conditions of the Creative Commons Attribution (CC BY) license (https:/ / creativecommons.org/licenses/by/ $4.0 /)$.

\begin{abstract}
The storage of hydrogen is the key technology for a sustainable future. We developed an in silico procedure, which is based on the combination of experimental and quantum-chemical methods. This method was used to evaluate energetic parameters for hydrogenation/dehydrogenation reactions of various pyrazine derivatives as a seminal liquid organic hydrogen carriers (LOHC), that are involved in the hydrogen storage technologies. With this in silico tool, the tempo of the reliable search for suitable LOHC candidates will accelerate dramatically, leading to the design and development of efficient materials for various niche applications.
\end{abstract}

Keywords: liquid organic hydrogen carriers; thermodynamic properties; quantum-chemical calculations

\section{Introduction}

Power production from renewable energy technologies suffers from systematic energy fluctuations and they can be improved by the storage of excess energy. Hydrogen has been considered as a possible energy carrier for various applications. Covalent bond usage of aromatic organic molecules is one of the promising options for hydrogen storage, because hydrogen can be stored by hydrogenation and it is released by the dehydrogenation, when the hydrogen is needed. Benzene and toluene can be considered as the first generation of liquid organic hydrogen carriers (LOHC), but the harsh reaction conditions (usually around $473 \mathrm{~K}$ ) of the dehydrogenation step have been unacceptable for designing industrial processes. In general, any olefin or aromatic compound can be considered a potential LOHC. Screening for suitable candidates for practical applications is, therefore, very demanding.

It was found that the introduction of a nitrogen atom to aromatic organic hydrides is effective for lowering of the dehydrogenation temperature [1]. This idea was realized in N-alkyl-carbazoles as the second generation of nitrogen-containing organic hydrides for hydrogen storage [2-4]. So far, however, no single material has been found that can meet numerous criteria expected for the inexpensive but effective hydrogen storage material that must consume and release $\mathrm{H}_{2}$ with fast kinetics at moderate temperatures of 350-400 K. Thus, the search for new LOHC systems based on abundant and inexpensive organic compounds with a high capacity to store and release hydrogen and ideally use the same catalyst to charge and discharge hydrogen under relatively mild conditions, and compatible with existing infrastructure for transport and refuelling, is a major challenge [5]. However, an unavoidable problem that limits progress in this area is the lack of experimental thermodynamic data for promising hydrogen-reach, as well as hydrogen-lean LOHC. There is no lack of various empirical group additivity (GA) methods [6-8] that can give satisfactory results for simple linear and not strained molecules. However, these methods generally fail for aromatic, branched, and strained cyclic molecules [9]. In a series 
of our recent studies, we successfully tested quantum-chemical composite methods of $G^{*}$ family to provide reliable gas phase thermochemical data for N-alkyl-carbazoles [2-4]. The hydrogenation/dehydrogenation reactions suitable for hydrogen storage, however, usually take place in the liquid phase. Therefore, the idea of combining the quantum chemical methods with a framework based on empirical, semi-empirical and theoretical approaches leading to thermodynamic data in the liquid phase seems to be a last resort in the situation with complete information deficit. The reliable thermodynamics of chemical reactions today can only be evaluated by a reasonable combination of experimental and computational methods. By computational methods we should understand not only the quantum chemical methods, but also all possible empirical, semi-empirical, and other theoretical methods. We define the interweaving of experimental methods with computational methods as an in silico-based procedure.

The aim of this paper is to offer a network of experimental thermochemical methods (combustion calorimetry, transpiration, tensimetry, and DSC) in combination with the high-level composite quantum-chemical methods (G4 and G3MP2) and a group-additivity method developed for prediction of vaporization enthalpies of LOHC. This network of experimental and in silico methods was used for the thermodynamic analysis of the energetics and feasibility of hydrogenation/dehydrogenation reactions for a series of substituted pyrazines and quinoxalines (see Figure 1) as possible LOHC candidates.
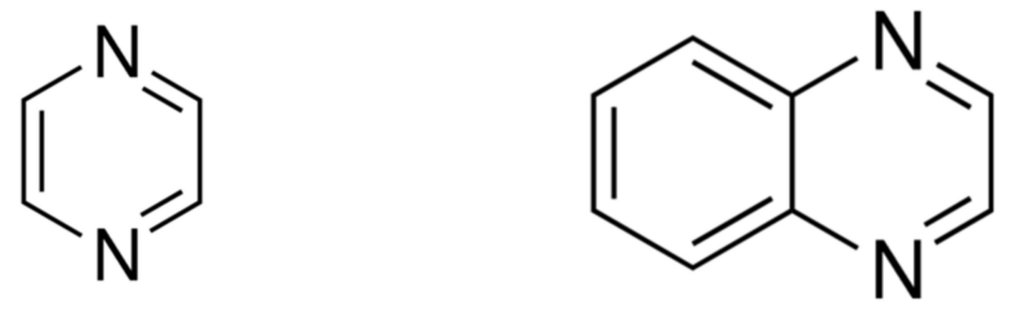

Figure 1. Pyrazine and quinoxaline (benzopyrazine): The potentially interesting core structures for LOHC alkyl-derivatives.

\section{Experimental Section}

\subsection{Materials and Purification}

The commercially available samples of pyrazine derivatives (see Table S1) have been used in this work. The liquid sample of 2-methyl-quinoxaline was additionally purified by the fractional distillation and the solid sample of 2,3-dimethyl-quinoxaline was purified by the fractional sublimation in a vacuum. No impurities (greater than 0.0002 mass fraction) could be detected in both samples used for the thermochemical measurements. The degree of purity was determined using a GC equipped with a FID. A capillary column HP- 5 was used with a column length of $30 \mathrm{~m}$, an inside diameter of $0.32 \mathrm{~mm}$, and a film thickness of $0.25 \mu \mathrm{m}$.

\subsection{Experimental and Theoretical Thermochemical Methods}

The gas-phase standard molar enthalpy of formation, $\Delta_{\mathrm{f}} H_{\mathrm{m}}^{\mathrm{o}}(\mathrm{g})$, of a compound under study is the comprehensive experimental thermochemical property that includes all enthalpies of phase transitions (sublimation, vaporization, and fusion) in combination with enthalpies of formation derived from the combustion enthalpy. Vapor pressures of methyl-quinoxalines at different temperatures were measured by the transpiration method. The standard molar enthalpy of vaporisation, $\Delta_{1}^{\mathrm{g}} H_{\mathrm{m}}^{\mathrm{o}}$, and the standard molar enthalpy of sublimation, $\Delta_{\mathrm{cr}}^{\mathrm{g}} H_{\mathrm{m}}^{\mathrm{o}}$, were derived from vapor pressures temperature dependences. The standard molar enthalpy of fusion, $\Delta_{\mathrm{cr}}^{1} H_{\mathrm{m}}^{\mathrm{o}}$, of 2,3-dimethyl-quinoxaline was measured by using the differential scanning calorimetry (DSC). The experimental procedures have been described elsewhere [10-13] and the necessary details are given in the electronic supporting information (ESI). 
We used quantum-chemical methods to get theoretical gas-phase enthalpies of formation, $\Delta_{\mathrm{f}} H_{\mathrm{m}}^{\mathrm{o}}(\mathrm{g})_{\text {theor }}$, of substituted pyrazines and amines. Calculations were performed with the Gaussian 09 series of programs [14]. An initial search for the stable conformers was performed with the force field method MM3 [15] and the b3lyp/6-31g(d,p) method [16]. Energies $E_{0}$ and enthalpies $H_{298}$ were calculated by using the composite G4 [17] and the G3MP2 methods [18] from Gaussian 09. Details on computational procedure were reported elsewhere [19]. The $H_{298}$-values were obtained according to the "rigid rotator"-"harmonic oscillator" approach embedded in the Gaussian 09. The enthalpies $\mathrm{H}_{298}$-values were finally converted to the $\Delta_{\mathrm{f}} H_{\mathrm{m}}^{\mathrm{o}}(\mathrm{g})_{\text {theor }}$ and discussed. Calculations were performed for the most stable conformer of each compound.

\section{Results and Discussion}

In general, any type of unsaturated compound could be considered a hydrogen carrier. The hydrogenation of the LOHC (or the regeneration of the spent form) is thermodynamically favorable, but the dehydrogenation of the LOHC (or the release of hydrogen) exhibits the reverse process, which becomes more favorable with increasing temperature. It was theoretically evaluated that an ideal LOHC is expected to have the hydrogenation enthalpy at a level of not higher than $40 \mathrm{~kJ} \cdot \mathrm{mol}^{-1} / \mathrm{H}_{2}$ [20]. However, the reaction enthalpy should not be significantly below $40 \mathrm{~kJ} \cdot \mathrm{mol}^{-1} / \mathrm{H}_{2}$ in order to avoid thermodynamic limitations in the regeneration step. Aliphatic unsaturated compounds cannot meet this requirement. In contrast, the aromatic nitrogen-containing aromatic compounds promise to overcome the thermodynamic limitations in the regeneration step. A major advantage of heterocyclic compounds over homocyclic aromatics is the lower temperature and enthalpy of reaction for the hydrogen release through dehydrogenation [20].

\subsection{Thermodynamic Background}

One of the typical for the hydrogen storage reactions is the hydrogenation/dehydrogenation of 2,5-dimethylpyrazine as it shown in Equation (1) below:

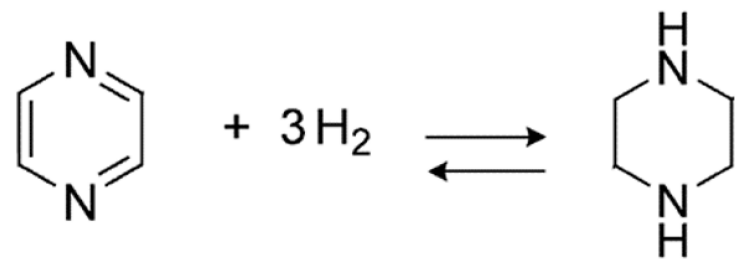

A chemical reaction basically takes place under thermodynamic and (or) kinetic control. The thermodynamic feasibility analysis of chemical processes enables the determination of the driving forces and could reduce the experimental efforts. Thermodynamic feasibility of a chemical process is determined by the sign of the Gibbs reaction energy, $\Delta_{\mathrm{r}} G_{\mathrm{m}}^{\mathrm{o}}$ according to the Gibbs-Helmholtz equation:

$$
\Delta_{\mathrm{r}} G_{\mathrm{m}}^{\mathrm{o}}=\Delta_{\mathrm{r}} H_{\mathrm{m}}^{\mathrm{o}}-T \times \Delta_{\mathrm{r}} S_{\mathrm{m}}^{\mathrm{o}}=-R T \times \ln K_{p}
$$

where $\Delta_{\mathrm{r}} G_{\mathrm{m}}^{\mathrm{o}}$ is the change in the free energy of a chemical reaction; $\Delta_{\mathrm{r}} H_{\mathrm{m}}^{\mathrm{o}}$ is the reaction enthalpy, and $\Delta_{\mathrm{r}} S_{\mathrm{m}}^{\mathrm{o}}$ is the change in the entropy of a chemical reaction. The negative $\operatorname{sign}\left(\Delta_{\mathrm{r}} G_{\mathrm{m}}^{\mathrm{o}}<0\right)$ provides a qualitative indication of the general feasibility. Moreover, the magnitude of the gas-phase thermodynamic equilibrium constant $K_{p}$ (at any temperature of interest $T$ ) provides quantitative insight into the possible yield of the desired product (e.g., for $K_{p}>10$ the yield is practically close to $99 \%$ ). As a rule, the thermodynamic calculations are initially carried out at the reference temperature $T=298 \mathrm{~K}$. Using the standard molar isobaric heat capacities $C_{p, \mathrm{~m}}^{\mathrm{o}}$ of reaction participants, the feasibility of the reaction at any desired temperature can be derived with the aid of Kirchhoff's law.

According to Equation (2), knowledge of standard molar enthalpies of formation and standard entropies of reaction participants is indispensable for the feasibility analysis. 
In the past decade, the high-level composite quantum-chemical methods become a valuable tool for obtaining theoretical $\Delta_{\mathrm{f}} H_{\mathrm{m}}^{\mathrm{o}}(\mathrm{g}, 298)$-values with so-called "chemical accuracy" of $4-5 \mathrm{~kJ} \cdot \mathrm{mol}^{-1}$ [21]. These QC methods differ considerably in terms of time and computing power. The QC calculations are currently being carried out successfully to obtain $\Delta_{\mathrm{f}} H_{\mathrm{m}}^{\mathrm{o}}(\mathrm{g})$ values for small- and medium-sized molecules.

Predicting the entropies (required for Equation (2)) and heat capacities (required for the Kirchhoff's Law) of organic molecules is undoubtedly a challenging task. In principle, they can be reliably calculated with help of quantum chemistry or using statistical mechanics if their structures, moments of inertia and vibration frequencies are known. The uncertainties of such calculations depend strongly on the size and flexibility of the molecules of interest. However, it is obvious from Equation (2) that the possible inaccuracy of the entropy predictions (calculated in usual units J.K $\mathrm{K}^{-1} \cdot \mathrm{mol}^{-1}$ ) compared to the enthalpic term (calculated in usual units $\mathrm{kJ} \cdot \mathrm{mol}^{-1}$ ) can be regarded as less pronounced. At least the inaccuracy of the entropy estimates is not crucial to get a correct trend of the $\Delta_{\mathrm{r}} G_{\mathrm{m}}^{\mathrm{o}}-$ value.

The gas-phase thermodynamic functions $\Delta_{\mathrm{r}} G_{\mathrm{m}}^{\mathrm{o}}$ and $K_{p}$ required for the thermodynamic analysis and optimization of the hydrogenation/dehydrogenation reactions can also be obtained with the high-level QC methods. For the practical applications the equilibrium constant, $K_{p}$, derived with the help of the quantum-chemistry have to be re-calculated to the liquid-phase thermodynamic equilibrium constant $K_{a}$. For example, for the hydrogenation reaction (1) the thermodynamic equilibrium constant $K_{a}$ in the liquid phase can be calculated by Equation (3):

$$
K_{a}=K_{p} \times \frac{p_{2,5-\text { dimethyl-pyrazine }} \times p_{H 2}}{p_{2,5 \text {-dimethyl-piperazine }}}
$$

where $p_{i}$ are the absolute vapor pressures of the pure reaction (1) participants $(i)$, which are either available in the literature or measured by any suitable method [22]. In addition, the QC calculations can be performed at any desired temperature and the desired $K_{a}$-values in the liquid phase can be evaluated in the temperature range of the practical application.

The heat management of the hydrogenation/dehydrogenation reactions is based on the standard molar enthalpies of formation of reaction participants. The latter values can be obtained with the help of modern high-level QC methods for the ideal gas state. However, the hydrogenation/dehydrogenation reactions are usually carried out in the liquid phase. Therefore, the theoretical enthalpies of formation $\Delta_{\mathrm{f}} H_{\mathrm{m}}^{\mathrm{o}}(\mathrm{g})$ of potential hydrogen carriers, which are calculated by using the QC method have to be re-calculated into the practically relevant liquid phase values, $\Delta_{\mathrm{f}} H_{\mathrm{m}}^{\mathrm{o}}(\mathrm{liq})$, as follows:

$$
\Delta_{\mathrm{f}} H_{\mathrm{m}}^{\mathrm{o}}(\text { liq })=\Delta_{\mathrm{f}} H_{\mathrm{m}}^{\mathrm{o}}(\mathrm{g})_{\mathrm{QC}}-\Delta_{\mathrm{l}}^{\mathrm{g}} H_{\mathrm{m}}^{\mathrm{o}}
$$

where $\Delta_{1}^{\mathrm{g}} H_{\mathrm{m}}^{\mathrm{o}}$ is the standard molar vaporization enthalpy of the compound of interest. It is important that all thermochemical properties involved in Equation (4) have to be referenced to the same temperature (e.g., to the reference temperature $T=298 \mathrm{~K}$ ). The $\Delta_{\mathrm{f}} H_{\mathrm{m}}^{\mathrm{o}}$ (liq, $298 \mathrm{~K}$ )-values derived by Equation (4) can be further used for estimation of reaction enthalpies $\Delta_{\mathrm{r}} H_{\mathrm{m}}^{\mathrm{o}}$ (liq, $298 \mathrm{~K}$ ) (according to the Hess's Law):

$$
\Delta_{\mathrm{r}} H_{\mathrm{m}}^{\mathrm{o}}(\text { liq })=\Delta_{\mathrm{f}} H_{\mathrm{m}}^{\mathrm{o}}(\text { liq, products })-\Delta_{\mathrm{f}} H_{\mathrm{m}}^{\mathrm{o}}(\text { liq, reactants })
$$

In our experiences, however, there is a more elegant and reliable access to the desired $\Delta_{\mathrm{r}} H_{\mathrm{m}}^{\mathrm{o}}($ liq, $298 \mathrm{~K})$-value over the theoretical enthalpy of a gas phase reaction, $\Delta_{\mathrm{r}} H_{\mathrm{m}}^{\mathrm{o}}(\mathrm{g})_{\mathrm{QC}}$. Indeed, the latter value can be calculated according to the Hess's Law directly from the $H_{298}$ values available in the output of the QC method. This gas-phase $\Delta_{\mathrm{r}} H_{\mathrm{m}}^{\mathrm{o}}(\mathrm{g})_{\mathrm{QC}}$-value is related to the liquid phase reaction enthalpy, $\Delta_{\mathrm{r}} H_{\mathrm{m}}^{\mathrm{o}}(\mathrm{liq})$, by equation:

$$
\Delta_{\mathrm{r}} H_{\mathrm{m}}^{\mathrm{o}}(\text { liq })=\Delta_{\mathrm{r}} H_{\mathrm{m}}^{\mathrm{o}}(\mathrm{g})_{\mathrm{QC}}-\sum_{i} v_{i} \Delta_{\mathrm{l}}^{\mathrm{g}} H_{\mathrm{m}, i}^{\mathrm{o}}
$$


where $\Delta_{1}^{\mathrm{g}} H_{\mathrm{m}, i}^{\mathrm{o}}$ are the molar enthalpies of vaporization of the pure reaction participants $i$ at the reference temperature $298 \mathrm{~K}$, and $v_{i}$ is the stoichiometric coefficient. The required vaporization enthalpies of compounds involved in the hydrogenation reactions are measurable [22] or they can be estimated with a reasonable accuracy, e.g., by the groupadditivity [6-9]. It is also important to note, that only in this case the $\Delta_{\mathrm{r}} H_{\mathrm{m}}^{\mathrm{o}}(\mathrm{g})_{\mathrm{QC}}$-values for hydrogenation/dehydrogenation reactions are calculated from enthalpies $H_{298}$ of the reaction participants, which are directly available from the Gaussian output. This option is valuable to overcome common ambiguities [23,24] associated with the quantum-chemical methods by using conventional isodesmic, homodesmic, etc. reactions [25]. Thus, the reasonable combination of experimental and theoretical methods opens up the possibility of a quick but reliable assessment of the energetics of reactions that are relevant for the hydrogen storage process.

In this work we used the data derived from traditional thermochemical methods (combustion calorimetry, vapor pressure measurements) together with the modern composite quantum-chemical methods G4 and G3MP2 methods to obtain Gibbs energies, reaction enthalpies, equilibrium constants, $K_{p}$, and $K_{a}$. These results, together with the thermodynamic functions of vaporization, derived from vapor pressure measurements, are used for the thermodynamic analysis of various nitrogen-containing LOHC hydrogenation reactions as follows.

\subsection{Thermodynamics of Liquid-Gas, Crystal-Gas, and Crystal-Liquid Phase Transitions}

Vapor pressures and vaporization enthalpies are an essential part of the thermodynamic analysis and they are involved in Equations (5) and (6). Results on the vapor pressure temperature dependences measured in this work by the transpiration method (see Table S2) have been used to derive the standard molar enthalpies of vaporization, $\Delta_{1}^{\mathrm{g}} H_{\mathrm{m}}^{\mathrm{o}}$, and standard molar sublimation enthalpies, $\Delta_{\mathrm{cr}}^{\mathrm{g}} H_{\mathrm{m}}^{\mathrm{o}}$, of pyrazine derivatives at different temperatures. Vapor pressures of 2-methylquinoxaline have been measured for the first time. Vapor pressures of pyrazine derivatives available in the original literature have been evaluated in the same way as our own results (see details in ESI). Results of the data evaluation are compiled in Table 1.

The single experimental vaporization enthalpy for quinoxaline was reported from the Correlation-Gas-Chromatography method [27]. The enthalpies of sublimation for 2,3dimethylquinoxaline compiled in Table 1 also agree within the combined experimental uncertainties. Vapor pressures for this compound measured in this work by the transpiration method are in agreement (see Figure S1) with those measured by the Knudsen mass-loss effusion technique [29]. Thus, the weighted average value $\Delta_{\mathrm{cr}}^{\mathrm{g}} H_{\mathrm{m}}^{\mathrm{o}}(298 \mathrm{~K})=(85.4 \pm 0.7) \mathrm{kJ} \cdot \mathrm{mol}^{-1}$ was derived and applied for further thermochemical calculations.

We have carefully collected available $\Delta_{\mathrm{cr}}^{\mathrm{g}} H_{\mathrm{m}}^{\mathrm{o}}(298 \mathrm{~K})$ and $\Delta_{1}^{\mathrm{g}} H_{\mathrm{m}}^{\mathrm{o}}(298 \mathrm{~K})$ data on alkylpyrazine derivatives (see Table S4) and together with our new complementary results on quinoxalines these data can be used for optimization of the hydrogenation/dehydrogenation reactions of LOHC.

Data on the thermodynamics of the solid-liquid phase transition for pyrazine derivatives are required for the mutual re-calculations of sublimation and vaporization enthalpies collected in Table 1 according to the general equation:

$$
\Delta_{\mathrm{cr}}^{\mathrm{g}} H_{\mathrm{m}}^{\mathrm{o}}=\Delta_{\mathrm{l}}^{\mathrm{g}} H_{\mathrm{m}}^{\mathrm{o}}+\Delta_{\mathrm{cr}}^{1} H_{\mathrm{m}}^{\mathrm{o}}
$$

Thermal behavior of 2,3-dimethylquinoxaline has been studied in this work for the first time. Available experimental data on enthalpies of fusion for methyl-substituted pyrazines and quinoxalines are compiled in Table 2. For thermochemical calculations, the experimental enthalpies of fusion measured at $T_{\text {fus }}$ were adjusted to the reference temperature $T=298 \mathrm{~K}$ (for details see ESI). 
Table 1. Compilation of enthalpies of vaporization/sublimation $\Delta_{\mathrm{l}, \mathrm{cr}}^{\mathrm{g}} H_{\mathrm{m}}^{\mathrm{o}}$ for pyrazine derivatives derived in this work and from the data available in the literature.

\begin{tabular}{|c|c|c|c|c|c|}
\hline Compound & Technique $^{\mathrm{a}}$ & T-Range & $\Delta_{\mathrm{l}, \mathrm{cr}}^{\mathrm{g}} H_{\mathrm{m}}^{\mathrm{o}}\left(T_{\mathrm{av}}\right)$ & $\Delta_{\mathrm{l}, \mathrm{cr}}^{\mathrm{g}} H_{\mathrm{m}}^{\mathrm{o}}(298 \mathbf{K})^{\mathrm{b}}$ & Ref. \\
\hline & & $\mathrm{K}$ & $\mathrm{kJ} \cdot \mathrm{mol}^{-1}$ & $\mathrm{~kJ} \cdot \mathrm{mol}^{-1}$ & \\
\hline quinoxaline (cr) & DC & 365 & - & $\begin{array}{c}(66.6 \pm 2.0) \\
71.1 \pm 0.9\end{array}$ & $\begin{array}{c}{[26]} \\
\text { Table } 2 \\
\end{array}$ \\
\hline 2-methylquinoxaline (liq) & $\mathrm{T}$ & $313.2-372.5$ & $63.8 \pm 0.3$ & $64.4 \pm 0.8$ & this work \\
\hline 2,3-dimethylquinoxaline (cr) & $\begin{array}{l}\mathrm{DC} \\
\mathrm{K} \\
\mathrm{T}\end{array}$ & $\begin{array}{c}383 \\
294.1-308.1 \\
313.2-372.5\end{array}$ & $\begin{array}{c}103.3 \pm 1.8 \\
87.7 \pm 0.8 \\
83.3 \pm 0.6\end{array}$ & $\begin{array}{c}85.8 \pm 1.8 \\
87.8 \pm 1.4 \\
84.6 \pm 0.8 \\
\mathbf{8 5 . 4} \pm \mathbf{0 . 7}^{\mathbf{c}}\end{array}$ & $\begin{array}{c}{[28]} \\
{[29]} \\
\text { this work } \\
\text { average }\end{array}$ \\
\hline 2,3-dimethylquinoxaline (liq) & & & & $66.7 \pm 1.3$ & Table 2 \\
\hline phenazine (cr) & & & & $95.9 \pm 0.4$ & {$[30]$} \\
\hline phenazine (liq) & & & & $78.7 \pm 2.3$ & [30] \\
\hline
\end{tabular}

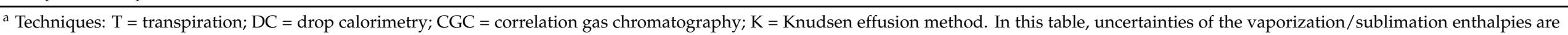

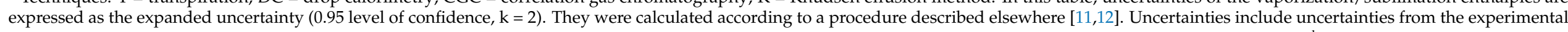

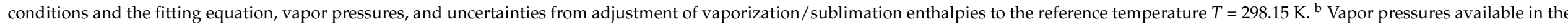

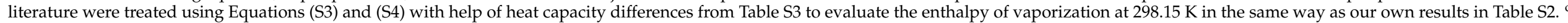

Weighted mean value (the uncertainty was taken as the weighing factor). Values highlighted in bold were recommended for thermochemical calculations.

Table 2. Compilation of thermodynamic data on $\mathrm{N}$-containing compounds (in $\left.\mathrm{kJ} \cdot \mathrm{mol}^{-1}\right)^{\mathrm{a}}$.

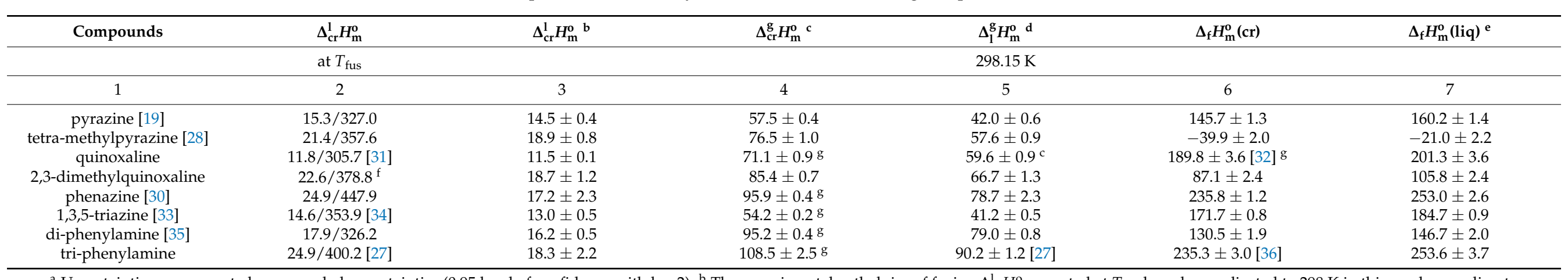

${ }^{a}$ Uncertainties are presented as expanded uncertainties $(0.95$ level of confidence with $\mathrm{k}=2){ }^{\mathrm{b}}$ The experimental enthalpies of fusion $\Delta_{\mathrm{cr}}^{\mathrm{l}} \mathrm{H}_{\mathrm{m}}^{\mathrm{o}}$ reported at $T_{\text {fus }}$ have been adjusted to $298 \mathrm{~K}$ in this work according to procedure developed by Chickos and Acree [37]. ${ }^{\mathrm{c}}$ From Table 1 or from the original literature given in column $1{ }^{\mathrm{d}}{ }^{\mathrm{C}}$ Calculated in this work as the difference between column 4 and 3 in this table. ${ }^{\mathrm{e}}$ Calculated in this work as the sum of column 3 and 6 in this table. ${ }^{f}$ This work ${ }^{g}$ Calculated in this work as the sum of column 3 and 5 in this table. 
The energetics of the solid-liquid phase transition for pyrazine derivatives are also required for the re-calculation of the standard molar enthalpies of formation in the crystal state, $\Delta_{\mathrm{f}} H_{\mathrm{m}}^{\mathrm{o}}(\mathrm{cr})$, into practically more relevant standard molar enthalpies of formation in the liquid state, $\Delta_{\mathrm{f}} H_{\mathrm{m}}^{\mathrm{o}}(\mathrm{liq})$, according to a general equation:

$$
\Delta_{\mathrm{f}} H_{\mathrm{m}}^{\mathrm{o}}(\mathrm{liq})=\Delta_{\mathrm{f}} H_{\mathrm{m}}^{\mathrm{o}}(\mathrm{cr})+\Delta_{\mathrm{cr}}^{1} H_{\mathrm{m}}^{\mathrm{o}}
$$

provided that all values are adjusted to the reference temperature $T=298 \mathrm{~K}$. The liquid phase enthalpies of formation of pyrazine derivatives are given in Table 2, column 7.

\subsection{Consistency of Vaporization Enthalpies}

Since the amount of experimental data on the vaporization/sublimation thermodynamics of quinoxalines is very limited, internal consistency needs to be proven using any kind of structure-property correlations. A valuable method to establish consistency of experimental data is the correlation gas-chromatography (CGC) [38]. In this method experimental enthalpies of vaporization $\Delta_{1}^{\mathrm{g}} H_{\mathrm{m}}^{\mathrm{o}}(298 \mathrm{~K})$ are correlated with the chromatographic Kovats indices $\left(J_{x}\right)$ on DB-1701 [39] (see Table 3). Earlier we demonstrated that vaporization enthalpy was linearly correlated with the $J_{x}$ in different homologous series of nitriles [40], aliphatic ethers [41], and alkylbenzenes [42].

Table 3. Correlation of vaporization enthalpies $\Delta_{1}^{\mathrm{g}} H_{\mathrm{m}}^{\mathrm{o}}(298.15 \mathrm{~K})$ of alkyl pyrazines and alkyl quinoxalines, with the Kovats indices on DB- $1701^{\mathrm{a}}$.

\begin{tabular}{|c|c|c|c|c|}
\hline & $J_{x}{ }^{\mathbf{a}}$ & $\Delta_{1}^{\mathbf{g}} H_{\mathrm{m}}^{\mathbf{o}}(298.15 \mathbf{K})_{\exp }{ }^{\mathbf{b}}$ & $\Delta_{1}^{\mathrm{g}} H_{\mathrm{m}}^{\mathbf{o}}(298.15 \mathrm{~K})_{\text {calc }^{c}}{ }^{\mathrm{c}}$ & \\
\hline & & $\mathrm{kJ} \cdot \mathrm{mol}^{-1}$ & $\mathrm{~kJ} \cdot \mathrm{mol}^{-1}$ & $\mathrm{~kJ} \cdot \mathrm{mol}^{-1}$ \\
\hline pyrazine & 822 & 42.0 & 41.2 & 0.8 \\
\hline methyl-pyrazine & 908 & 44.0 & 44.4 & -0.4 \\
\hline 2,5-di-methyl-pyrazine & 988 & 48.2 & 47.4 & 0.6 \\
\hline 2,6-di-methyl-pyrazine & 991 & 45.3 & 47.5 & -2.2 \\
\hline ethyl-pyrazine & 994 & 48.4 & 47.6 & 0.7 \\
\hline 2,3-di-methyl-pyrazine & 1000 & 47.8 & 47.8 & 0.0 \\
\hline tri-methyl-pyrazine & 1075 & 52.2 & 50.6 & 1.2 \\
\hline 2,3-di-ethyl-pyrazine & 1170 & 53.8 & 54.1 & -0.3 \\
\hline tetra-methyl-pyrazine & 1274 & 57.6 & 57.9 & -0.3 \\
\hline quinoxaline & 1327 & & 59.9 & -0.3 \\
\hline 2-methyl-quinoxaline & 1421 & & 63.3 & 1.1 \\
\hline 2,3-di-methyl-quinoxaline & 1506 & & 66.5 & 0.2 \\
\hline
\end{tabular}

a Data on DB-1701 [39]. b Experimental data from Table S4. c Calculated using equation: $\Delta_{1}^{\mathrm{g}} H_{\mathrm{m}}^{\mathrm{o}}$ $(298.15 \mathrm{~K}) /\left(\mathrm{kJ} \cdot \mathrm{mol}^{-1}\right)=10.9+0.0369 \times J_{x}$ with $\left(R^{2}=0.985\right)$.

For correlation with $\Delta_{1}^{\mathrm{g}} H_{\mathrm{m}}^{\mathrm{o}}(298 \mathrm{~K})$-values listed in Table 1 and Table S4, we have collected Kovats indices for low polarity gas-chromatographic column DB-1701 (see Table 3). It has turned out that the $\Delta_{1}^{\mathrm{g}} H_{\mathrm{m}}^{\mathrm{o}}(298 \mathrm{~K})$-values of pyrazine derivatives and quinoxalines exhibit very good linear correlations with the $J_{x}$-values:

$$
\Delta_{\mathrm{l}}^{\mathrm{g}} H_{\mathrm{m}}^{\mathrm{o}}(298.15 \mathrm{~K}) /\left(\mathrm{kJ} \cdot \mathrm{mol}^{-1}\right)=10.9+0.0369 \times J_{x} \text { with }\left(R^{2}=0.985\right)
$$

The high correlation coefficient $R^{2}=0.985$ of the $\Delta_{1}^{\mathrm{g}} H_{\mathrm{m}}^{\mathrm{o}}(298 \mathrm{~K})=f\left(J_{x}\right)$ dependence proves the reliability and internal consistency of the enthalpies of vaporization evaluated in the Table 1. The uncertainties of the correlated results derived in Table 3 were rated with $\pm 1 \mathrm{~kJ} \cdot \mathrm{mol}^{-1}$.

It is also important to show the internal consistency of the datasets of the quinoline and its methyl derivatives as well as the pyrazine and its methyl derivatives, as shown in Figure S2. The difference between pairs of molecules is not expected to be the same, but the general trends appear to be consonant within a range of pyrazines, quinoxalines, and benzenes (see Figure S2). 
Vapor pressures and thermodynamics of solid-vapor, liquid-vapor, and solid-liquid phase transitions of pyrazine and quinoxaline derivatives, which were evaluated in this work (see Tables 1-3) can be recommended for the thermodynamic analysis of reactions hydrogenation/dehydrogenation reactions and for the calculations of the liquid-phase thermodynamic equilibrium constants $K_{a}$ of these reactions in combination with the quantumchemical methods as follows in Sections 3.7 and 3.8.

\subsection{Standard Molar Enthalpies of Formation of Pyrazine Derivatives}

Standard molar enthalpies of formation of pyrazines and quinoxalines are required for the thermodynamic analysis of the hydrogenation/dehydrogenation reactions according to the Hess's Law (Equation (5)) or according to Equation (6). The thermochemistry of pyrazine and quinoxaline derivatives has been studied intensively in established laboratories in Porto $[26,28,29,43,44]$. The available experimental results together with our new measurements are compiled in Table 4.

The results for $\Delta_{\mathrm{f}} H_{\mathrm{m}}^{\mathrm{o}}$ (liq or cr) from the combustion calorimetry, which are collected in Table 4, and the vaporization/sublimation enthalpies of pyrazine derivatives, which were evaluated and averaged in this work (see Table 1), were used together for the further calculation of the experimental gas phase standard molar enthalpies of formation, $\Delta_{\mathrm{f}} H_{\mathrm{m}}^{\mathrm{o}}(\mathrm{g})_{\exp }$ at $298 \mathrm{~K}$ (see Table 4, column 4). Since the available for each compound data on $\Delta_{\mathrm{f}} H_{\mathrm{m}}^{\mathrm{o}}$ (liq or cr) compiled in Table 4, column 2 are originated from single sources, they were validated with help of the QC calculations. An agreement or disagreement between the experimental (Table 4, column 4) and theoretical (Table 4, column 5) $\Delta_{\mathrm{f}} H_{\mathrm{m}}^{\mathrm{o}}(\mathrm{g})_{\mathrm{G} 4}$-values could provide a criterion for the mutual validation for both results.

In order to convert the $H_{298}$ values into theoretical standard enthalpies of formation $\Delta_{\mathrm{f}} H_{\mathrm{m}}^{\mathrm{o}}(\mathrm{g})$ we used the atomization procedure. It is known that enthalpies of formation resulting from the atomization process have to be corrected for a systematic shift $[23,24]$. In order to "correct" the theoretical $\Delta_{\mathrm{f}} H_{\mathrm{m}}^{\mathrm{o}}(\mathrm{g})_{\mathrm{G} 4}$ values calculated by the atomization procedure, we used the linear correlation:

$$
\Delta_{\mathrm{f}} H_{\mathrm{m}}^{\mathrm{o}}(\mathrm{g})_{\exp } / \mathrm{kJ} \cdot \mathrm{mol}^{-1}=(1.010 \pm 0.003) \Delta_{\mathrm{f}} H_{\mathrm{m}}^{\mathrm{o}}(\mathrm{g}) \mathrm{G}_{4}+(0.7 \pm 0.4) \text { with } R^{2}=0.9998
$$

developed in our previous work [19] with a set of 18 small heterocyclic compounds similar in shape to the diazines. The "corrected" in this way theoretical $\Delta_{\mathrm{f}} H_{\mathrm{m}}^{\mathrm{o}}(\mathrm{g})_{\mathrm{G} 4}$ values (Table 4, column 5) are in a good agreement with the experiment (within the boundaries of the experimental uncertainties). This agreement can be considered as an indicator for the mutual consistency of the experimental and theoretical results evaluated in this work. 
Table 4. Thermochemical data at $T=298 \mathrm{~K}\left(p^{\circ}=0.1 \mathrm{MPa}\right)$ for pyrazine derivatives $\left(\text { in } \mathrm{kJ} \cdot \mathrm{mol}^{-1}\right)^{\mathrm{a}}$.

\begin{tabular}{|c|c|c|c|c|c|}
\hline Compounds & $\Delta_{\mathrm{f}} H_{\mathrm{m}}^{\mathrm{o}}$ (liq or cr) & $\Delta_{1, \mathrm{cr}}^{\mathrm{g}} H_{\mathrm{m}}^{\mathrm{o}} \mathrm{b}$ & $\Delta_{\mathrm{f}} H_{\mathrm{m}}^{\mathrm{o}}(\mathrm{g})_{\exp }$ & $\Delta_{\mathrm{f}} H_{\mathrm{m}}^{\mathrm{o}}(\mathrm{g}) \mathrm{G}_{4}{ }^{\mathrm{c}}$ & d \\
\hline 1 & 2 & 3 & 4 & 5 & 6 \\
\hline pyrazine $(\mathrm{cr})$ & $145.7 \pm 1.3[19]$ & $57.5 \pm 0.4$ & $203.2 \pm 1.5$ & 206.7 & -3.5 \\
\hline methylpyrazine (liq) & $(118.7 \pm 3.5)^{\mathrm{e}}$ & $44.0 \pm 0.3$ & - & 162.7 & - \\
\hline 2,3-dimethylpyrazine (liq) & $73.4 \pm 2.0[28]$ & $47.8 \pm 1.0$ & $121.2 \pm 2.2$ & 120.7 & 0.5 \\
\hline 2,5-dimethylpyrazine (liq) & $67.0 \pm 2.0[43]$ & $48.2 \pm 0.5$ & $115.2 \pm 2.0$ & 119.7 & -4.5 \\
\hline 2,6-dimethylpyrazine (cr) & $(55.5 \pm 3.8)^{e}$ & $63.5 \pm 1.4$ & - & 119.0 & - \\
\hline trimethylpyrazine (liq) & $20.4 \pm 2.2[28]$ & $52.2 \pm 0.8$ & $72.6 \pm 2.3$ & 77.3 & -4.7 \\
\hline tetramethylpyrazine $(\mathrm{cr})$ & $-39.9 \pm 2.0[28]$ & $76.5 \pm 1.0$ & $36.6 \pm 2.2$ & 36.9 & -0.3 \\
\hline ethylpyrazine (liq) & $98.1 \pm 2.1[44]$ & $48.4 \pm 0.9$ & $146.5 \pm 2.3$ & 141.0 & 5.5 \\
\hline n-propylpyrazine (liq) & $(66.5 \pm 3.6)^{e}$ & $51.9 \pm 1.0$ & - & 118.4 & - \\
\hline 2,3-diethylpyrazine (liq) & $27.6 \pm 2.4[44]$ & $53.8 \pm 1.1$ & $81.4 \pm 2.6$ & 81.3 & 0.1 \\
\hline quinoxaline (cr) & $(189.8 \pm 3.6)^{e}$ & $71.1 \pm 0.9^{\mathrm{f}}$ & $262.3 \pm 4.2[29]$ & 260.9 & 1.4 \\
\hline 2-methylquinoxaline (liq) & $(151.5 \pm 3.6)^{e}$ & $64.4 \pm 0.8$ & - & 215.9 & - \\
\hline 2,3-dimethylquinoxaline (cr) & $87.1 \pm 2.4[28]$ & $85.4 \pm 0.7$ & $172.5 \pm 2.5$ & 171.2 & 1.3 \\
\hline phenazine $(\mathrm{cr})$ & $235.8 \pm 1.2[30]$ & $95.9 \pm 0.4$ & $331.7 \pm 1.3$ & 329.3 & 2.4 \\
\hline
\end{tabular}

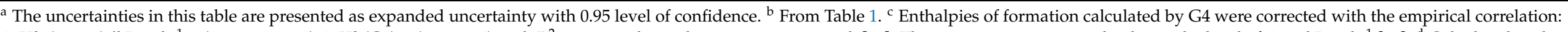

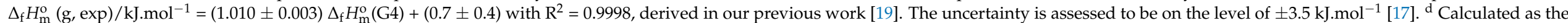
difference column 4 and 5. ${ }^{\mathrm{e}}$ Calculated as the difference column 5 and $3 .{ }^{\mathrm{f}}$ From Table 2. 


\subsection{Standard Molar Enthalpies of Formation of Hydrogenated Pyrazines as LOHC}

Standard molar enthalpies of formation of hydrogenated pyrazines (e.g., piperazine as fully hydrogenated pyrazine) are also required for the thermodynamic analysis of the hydrogenation/dehydrogenation reactions according to the Hess's Law (Equation (5)) or according to Equation (6). For the sake of clarity, the structures of hydrogenated pyrazine derivatives are given in Table 5 , column 2 . It has turned out that the thermochemical data on piperazine derivatives are only available for the piperazine itself $[45,46]$ (see Table 5). However, in our recent work we have shown that the group-additivity method and quantum-chemical calculations can provide reliable enthalpies of vaporization and gas-phase enthalpies of formation of various aliphatic cyclic amines (cyclohexanamine, $\mathrm{N}$-methyl-cyclohexanamine, $\mathrm{N}, \mathrm{N}$-dimethyl-cyclohexanamine, and $\mathrm{N}$-cyclohexylcyclohexanamine) [47]. The latter structures are related to the hydrogenated pyrazines investigated in this work. In the present work we propagate this combination of empirical and quantum chemical methods in order to derive the enthalpies of liquid phase formation of the LOHC candidates.

Table 5. Thermochemical data at $T=298 \mathrm{~K}\left(p^{\circ}=0.1 \mathrm{MPa}\right)$ for the hydrogenated pyrazine derivatives $\left(\text { in } \mathrm{kJ} \cdot \mathrm{mol}^{-1}\right)^{\mathrm{a}}$.

\begin{tabular}{|c|c|c|c|c|}
\hline Compounds & Structure & $\Delta_{\mathrm{f}} H_{\mathrm{m}}^{\mathrm{o}}(\mathrm{liq})$ & $\Delta_{1}^{\mathrm{g}} H_{\mathrm{m}}^{\mathrm{o} \quad \mathrm{b}}$ & $\Delta_{\mathrm{f}} H_{\mathrm{m}}^{\mathrm{o}}(\mathrm{g}) \mathrm{G}_{4}{ }^{\mathrm{c}}$ \\
\hline 1 & 2 & 3 & 4 & 5 \\
\hline piperazine & & $-18.5 \pm 0.8[45]$ & $50.1 \pm 1.9[46]$ & $32.0^{\mathrm{d}}$ \\
\hline 2-methylpiperazine & & $(-60.4 \pm 3.6)^{e}$ & $50.9 \pm 1.0$ & -9.5 \\
\hline $\begin{array}{c}2,3- \\
\text { dimethylpiperazine }\end{array}$ & & $(-94.5 \pm 3.6)^{e}$ & $51.6 \pm 1.0$ & -42.9 \\
\hline $\begin{array}{c}2,5- \\
\text { dimethylpiperazine }\end{array}$ & & $(-98.1 \pm 3.6)^{e}$ & $52.4 \pm 1.0$ & -45.7 \\
\hline trimethylpiperazine & & $(-135.3 \pm 3.6)^{e}$ & $53.0 \pm 1.0$ & -82.3 \\
\hline tetramethylpiperazine & & $(-171.8 \pm 3.6)^{\mathrm{e}}$ & $53.6 \pm 1.0$ & -118.2 \\
\hline perhydroquinoxaline & & $(-107.5 \pm 3.6)^{\mathrm{e}}$ & $63.7 \pm 1.0$ & -43.8 \\
\hline $\begin{array}{l}\text { 2-methyl- } \\
\text { perhydroquinoxaline }\end{array}$ & & $(-148.8 \pm 3.6)^{e}$ & $65.1 \pm 1.0$ & -83.7 \\
\hline $\begin{array}{l}\text { 2,3-dimethyl- } \\
\text { perhydroquinoxaline }\end{array}$ & & $(-184.6 \pm 3.6)^{e}$ & $65.7 \pm 1.0$ & -118.9 \\
\hline perhydrophenazine & & $(-198.0 \pm 3.6)^{e}$ & $77.9 \pm 1.0$ & -120.1 \\
\hline
\end{tabular}

a The uncertainties in this table are presented as expanded uncertainty with 0.95 level of confidence. ${ }^{\mathrm{b}}$ Vaporization enthalpies estimated using group-contributions listed in Table S6. ${ }^{\mathrm{c}}$ Enthalpies of formation calculated by G4 were corrected with the empirical correlation according to Equation (10). The uncertainty is assessed to be on the level of $\pm 3.5 \mathrm{~kJ} \cdot \mathrm{mol}^{-1}$ [17]. ${ }^{\mathrm{d}}$ For comparison for piperazine $\Delta_{\mathrm{f}} H_{\mathrm{m}}^{\mathrm{o}}(\mathrm{g})_{\exp }=31.6 \pm 2.1 \mathrm{~kJ} \cdot \mathrm{mol}^{-1}$ [46]. ${ }^{\mathrm{e}}$ Calculated as the difference column 5 and 4 . 
The available experimental gas-phase enthalpy of formation of piperazine have been validated with help of the G4 calculations. A very good agreement between the experimental $\Delta_{\mathrm{f}} H_{\mathrm{m}}^{\mathrm{o}}(\mathrm{g})_{\mathrm{exp}}=31.6 \pm 2.1 \mathrm{~kJ} \cdot \mathrm{mol}^{-1}$ and theoretical $\Delta_{\mathrm{f}} H_{\mathrm{m}}^{\mathrm{o}}(\mathrm{g})_{\mathrm{G} 4}=32.0 \pm 3.5 \mathrm{~kJ} \cdot \mathrm{mol}^{-1}(\mathrm{see}$ Table 5) clearly demonstrated the ability of the high-level composite method G4 to provide reliable energetics of the hydrogenated pyrazine derivatives in the gas phase. However, in order to get the liquid phase $\Delta_{\mathrm{f}} H_{\mathrm{m}}^{\mathrm{o}}$ (liq, $298 \mathrm{~K}$ )-values according to Equation (4), vaporization enthalpies of hydrogenated pyrazine derivatives are required. In a series of our recent papers [48-52] we have developed group-additivity parameters for prediction of $\Delta_{1}^{\mathrm{g}} H_{\mathrm{m}}^{\mathrm{o}}(298 \mathrm{~K})$-values of aliphatic nitrogen-containing compounds. Compilation of the group contributions required for estimation of vaporization enthalpies of different cyclic amines is given in Table S6. These increments have been used to obtain $\Delta_{1}^{\mathrm{g}} H_{\mathrm{m}}^{\mathrm{o}}(298 \mathrm{~K})$ values for alkyl-piperazines listed in Table 5, column 4 . The validation of the increments is shown in Table S7. Finally, in order to derive the liquid phase enthalpies of formation of hydrogenated pyrazines, required for thermodynamic analysis of the LOHC practical applications, we have combined the theoretical $\Delta_{\mathrm{f}} H_{\mathrm{m}}^{\mathrm{o}}(\mathrm{g}, 298 \mathrm{~K})$-values from QC with vaporization enthalpies estimated by the group additivity procedure. These $\Delta_{\mathrm{f}} H_{\mathrm{m}}^{\mathrm{o}}$ (liq, 298 K)-values are given in Table 5, column 3.

\subsection{Energetics of the Hydrogenation Process: Structure-Energetics Relationships}

When using LOHC technology for on-board energy supply in road vehicles, the energetics of the dehydrogenation/hydrogenation reaction is essential for optimizing the temperature range and the power density of the conversion units. Unfortunately, the body of thermochemical data on various LOHC compounds is very limited. For this reason, two methods (using Equations (5) and (6)) given in Section 3.1 for evaluating the reaction enthalpies $\Delta_{\mathrm{r}} H_{\mathrm{m}}^{\mathrm{o}}$ (liq) have to be thoroughly validated with reliable data before using for a general thermodynamic analysis.

As an attestation, we used well-established experimental thermochemical data for piperazine $\Delta_{\mathrm{f}} H_{\mathrm{m}}^{\mathrm{o}}($ liq, $298 \mathrm{~K})=(-18.8 \pm 0.8) \mathrm{kJ} \cdot \mathrm{mol}^{-1}[46]$ and pyrazine $\Delta_{\mathrm{f}} H_{\mathrm{m}}^{\mathrm{o}}(\mathrm{liq}, 298 \mathrm{~K})$ $=(161.2 \pm 1.7) \mathrm{kJ} \cdot \mathrm{mol}^{-1}$ [19] in order to calculate the experimental reaction enthalpy, $\Delta_{\mathrm{r}} H_{\mathrm{m}}^{\mathrm{o}}$ $(298 \mathrm{~K})=(-180.0 \pm 1.9) \mathrm{kJ} \cdot \mathrm{mol}^{-1}$ according to Equation (5) for the following reaction:

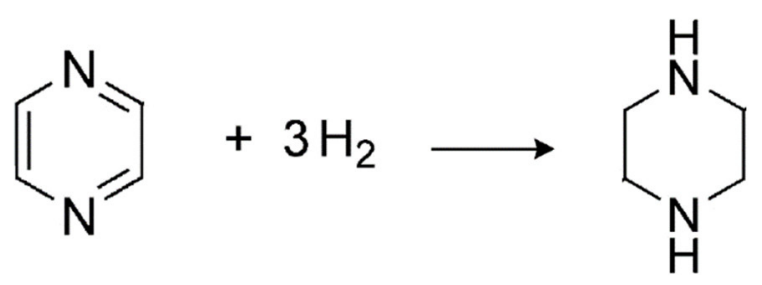

$$
\mathrm{C}_{4} \mathrm{H}_{4} \mathrm{~N}_{2}(\text { liq })+3 \mathrm{H}_{2}(\mathrm{~g})=\mathrm{C}_{4} \mathrm{H}_{10} \mathrm{~N}_{2}\left(\text { liq) with } \Delta_{\mathrm{r}} H_{\mathrm{m}}^{\mathrm{o}}(\text { liq })=-180.0 \pm 1.9 \mathrm{~kJ} \cdot \mathrm{mol}^{-1}\right.
$$

For comparison, the practically indistinguishable reaction enthalpy $\Delta_{\mathrm{r}} H_{\mathrm{m}}^{\mathrm{o}}$ (liq) $=$ $-178.7 \mathrm{~kJ} \cdot \mathrm{mol}^{-1}$ (see Table 6) was calculated for this reaction according to Equation (6) by using the G4 calculated gas-phase enthalpy of reaction $\Delta_{\mathrm{r}} H_{\mathrm{m}}^{\mathrm{o}}(\mathrm{g})_{\mathrm{G} 4}$ combined with the experimental vaporization enthalpies of reaction participants. 
Table 6. Reaction enthalpies of hydrogenation/dehydrogenation of pyrazine derivatives, at $T=298 \mathrm{~K}$ in $\mathrm{kJ} \cdot \mathrm{mol}^{-1}$.

\begin{tabular}{|c|c|c|c|c|c|}
\hline Compounds $^{a}$ & $\Delta_{1}^{\mathrm{g}} H_{\mathrm{m}}^{\mathrm{o}} \mathrm{b}$ & $\Delta_{1}^{\mathrm{g}} H_{\mathrm{m}}^{\mathrm{o}} \mathrm{c}$ & $\Delta_{\mathrm{r}} H_{\mathrm{m}}^{\mathrm{o}}(\mathrm{g}) \mathrm{G}_{4}{ }^{\mathrm{d}}$ & $\Delta_{\mathrm{r}} H_{\mathrm{m}}^{\mathrm{o}}(\mathrm{liq}) \mathrm{G}_{4} \mathrm{e}$ & $\Delta_{\mathrm{r}} H_{\mathrm{m}}^{\mathbf{o}}\left(\mathbf{H}_{2}\right)^{\mathbf{f}}$ \\
\hline pyrazine & 42.0 & $50.1[46]$ & -168.7 & -178.7 & -59.7 \\
\hline methylpyrazine & 44.0 & 50.9 & -166.3 & -173.2 & -57.7 \\
\hline $\begin{array}{c}2,3- \\
\text { dimethylpyrazine }\end{array}$ & 47.8 & 51.6 & -157.8 & -161.6 & -53.9 \\
\hline $\begin{array}{c}2,5- \\
\text { dimethylpyrazine }\end{array}$ & 48.0 & 52.4 & -159.5 & -163.9 & -54.6 \\
\hline $\begin{array}{l}\text { tri- } \\
\text { methylpyrazine }\end{array}$ & 51.8 & 53.0 & -153.8 & -155.0 & -51.7 \\
\hline $\begin{array}{c}\text { tetra- } \\
\text { methylpyrazine }\end{array}$ & 57.6 & 53.6 & -149.4 & -145.4 & -48.5 \\
\hline $\begin{array}{c}\text { tert- } \\
\text { butylpyrazine }\end{array}$ & 50.5 & 66.5 & -159.8 & -175.8 & -58.6 \\
\hline $\begin{array}{c}\text { 2,6-di-tert- } \\
\text { butylpyrazine }\end{array}$ & 58.4 & 82.2 & $-132.3 \mathrm{~g}$ & -156.1 & -52.0 \\
\hline 1,3,5-triazine & $41.2[53]$ & 55.3 & -129.0 & -143.1 & -47.7 \\
\hline
\end{tabular}

${ }^{a}$ Only the fully dehydrogenated molecules are shown. Details are given in Table S8. ${ }^{b}$ For the fully dehydrogenated molecules. Data from Table 1. ${ }^{c}$ For the fully-hydrogenated molecules. Vaporization enthalpies estimated using group-contributions listed in Table S6. ${ }^{\mathrm{d}}$ Calculated directly from $\mathrm{H}_{298}$-values of the hydrogenation reaction participants. ${ }^{\mathrm{e}}$ Calculated according to Equation (6). ${ }^{\mathrm{f}}$ Reaction enthalpy per mole of hydrogen in $\mathrm{kJ} \cdot \mathrm{mol}^{-1} / \mathrm{H}_{2}$. The uncertainty is assessed to be on the level of $\pm 3.5 \mathrm{~kJ} \cdot \mathrm{mol}^{-1}$. ${ }^{9}$ Calculated by G3MP2 according to the Hess's Law applied to reaction: 2,6-di-tert-butyl-pyrazine + benzene $=2$-tert-butyl-pyrazine + tert-butyl-benzene. Data for tert-butyl-benzene were taken from [54].

Very good agreement between the "pure" experimental $\Delta_{\mathrm{r}} H_{\mathrm{m}}^{\mathrm{o}}$ (liq)-value, which was derived using the Hess's Law, and the theoretical value, which was estimated by Equation (6), was demonstrated for the typical reaction of the pyrazine hydrogenation/dehydrogenation (see Equation (11) and Table 6). This fact can serve as a successful validity test for applying the combination of QC and group additivity methods to reliably predict the enthalpies of the hydrogenation/dehydrogenation reaction.

An important remark should be made about the quantum chemical calculations. The theoretical values, $\Delta_{\mathrm{r}} H_{\mathrm{m}}^{\mathrm{o}}(\mathrm{g})_{\mathrm{G} 4}$, of the gas phase hydrogenation reaction derived in Table 6 and discussed above were calculated according to the Hess's Law from the $H_{298}$ values calculated by the G4 method which are directly available from the Gaussian 09 output. This way to get the $\Delta_{\mathrm{r}} H_{\mathrm{m}}^{\mathrm{o}}(\mathrm{g})_{\mathrm{G} 4}$-values is preferable in comparison (see details in ESI) to other options to calculate the reaction enthalpy based on the Hess's Law applied for the theoretical enthalpies of formation, $\Delta_{\mathrm{f}} H_{\mathrm{m}}^{\mathrm{o}}(\mathrm{g}, 298 \mathrm{~K})$, calculated by any common procedures (atomization, isodesmic reactions, homodesmic reactions, etc.) [25]. This way is advantageous in order to overcome ambiguities associated with the quantum-chemical methods for calculations of $\Delta_{\mathrm{f}} H_{\mathrm{m}}^{\mathrm{o}}(\mathrm{g}, 298 \mathrm{~K})$, by using conventional reactions [23-25].

The hydrogenation of aromatic compounds is a highly exothermic process and careful heat management is essential for the safety of the practical applications. In order to reveal the structure-energetics relationships for the hydrogenation reactions, the $\Delta_{\mathrm{r}} H_{\mathrm{m}}^{\mathrm{o}}$ (liq) G4 $^{-v}$ alues for series of pyrazine derivatives (Table 6), quinoxaline derivatives (Table 7), pyridine derivatives (Table 8), and aniline derivatives (Table 9). 
Table 7. Reaction enthalpy of hydrogenation/dehydrogenation of quinoxaline derivatives, at $T=298 \mathrm{~K}\left(p^{\circ}=0.1 \mathrm{MPa}\right)$ in $\mathrm{kJ} \cdot \mathrm{mol}^{-1}$.

\begin{tabular}{|c|c|c|c|c|c|}
\hline Compounds ${ }^{a}$ & $\Delta_{1}^{\mathrm{g}} H_{\mathrm{m}}^{\mathrm{o}} \mathrm{b}$ & $\Delta_{1}^{\mathrm{g}} H_{\mathrm{m}}^{\mathrm{o}}{ }^{\mathrm{c}}$ & $\Delta_{\mathrm{r}} H_{\mathrm{m}}^{\mathrm{o}}(\mathrm{g}) \mathrm{G}_{4}{ }^{\mathrm{d}}$ & $\Delta_{\mathrm{r}} H_{\mathrm{m}}^{\mathrm{o}}(\mathrm{liq}) \mathrm{G}_{4} \mathrm{e}$ & $\Delta_{\mathrm{r}} H_{\mathrm{m}}^{\mathrm{o}} / \mathbf{H}_{2}$ \\
\hline quinoxaline & 58.7 & 63.7 & -294.7 & -299.7 & -59.9 \\
\hline 2-methylquinoxaline & 64.4 & 65.1 & -289.7 & -290.4 & -58.1 \\
\hline $\begin{array}{c}2,3- \\
\text { dimethylquinoxaline }\end{array}$ & 66.7 & 65.7 & -280.3 & -279.3 & -55.9 \\
\hline $\begin{array}{l}\text { 2,6-dimethyl-1,5- } \\
\text { naphthyridine }\end{array}$ & 66.7 & 66.5 & -280.6 & -290.2 & -58.0 \\
\hline phenazine & $78.7^{g}$ & 77.9 & -435.1 & -434.3 & -62.0 \\
\hline
\end{tabular}

a Only the fully dehydrogenated molecules are shown. Details are given in Tables S5 and S9. ${ }^{\mathrm{b}}$ For the fully dehydrogenated molecules. Data from Table $1 .{ }^{c}$ For the fully-hydrogenated molecules. Vaporization enthalpies estimated using group-contributions listed in Table S6. ${ }^{\mathrm{d}}$ Calculated directly from $\mathrm{H}_{298}$-values of the hydrogenation reaction participants. ${ }^{e}$ Calculated according to Equation (6). The uncertainty is assessed to be on the level of $\pm 3.5 \mathrm{~kJ} \cdot \mathrm{mol}^{-1}$. ${ }^{\mathrm{f}}$ Reaction enthalpy per mole of hydrogen in $\mathrm{kJ} \cdot \mathrm{mol}^{-1} / \mathrm{H}_{2} . \mathrm{g}$ from Table 4.

Table 8. Reaction enthalpy of hydrogenation/dehydrogenation of pyridine derivatives, at $T=298 \mathrm{~K}$ $\left(p^{\circ}=0.1 \mathrm{MPa}\right)$ in $\mathrm{kJ} \cdot \mathrm{mol}^{-1}$.

\begin{tabular}{|c|c|c|c|c|c|}
\hline Compounds ${ }^{a}$ & $\Delta_{1}^{\mathrm{g}} H_{\mathrm{m}}^{\mathrm{o} \quad \mathrm{b}}$ & $\Delta_{1}^{\mathrm{g}} H_{\mathrm{m}}^{\mathrm{o}} \mathrm{c}$ & $\Delta_{\mathrm{r}} H_{\mathrm{m}}^{\mathrm{o}}(\mathrm{g}) \mathrm{G}_{4}{ }^{\mathrm{d}}$ & $\Delta_{\mathrm{r}} H_{\mathrm{m}}^{\mathrm{o}}(\mathrm{liq}) \mathrm{G}_{4} \mathrm{e}$ & $\Delta_{\mathrm{r}} H_{\mathrm{m}}^{\mathrm{o}} / \mathrm{H}_{2}{ }^{\mathrm{f}}$ \\
\hline pyridine & 40.2 & $39.3^{g}$ & -178.6 & -177.7 & -59.2 \\
\hline 2-methylpyridine & 42.5 & $40.5^{\mathrm{g}}$ & -174.7 & -172.7 & -57.6 \\
\hline 4-methylpyridine & 44.9 & $40.6^{\mathrm{h}}$ & -175.1 & -170.8 & -56.9 \\
\hline 2,6-dimethylpyridine & 46.0 & $42.4^{\mathrm{h}}$ & -170.9 & -167.3 & -55.8 \\
\hline 2-tert-butylpyridine & 42.7 & 57.5 & -169.1 & -183.9 & -61.3 \\
\hline 4-tert-butylpyridine & 54.4 & 54.2 & -170.0 & -169.8 & -56.6 \\
\hline $\begin{array}{c}\text { 2,6-di-tert- } \\
\text { butylpyridine }\end{array}$ & 56.6 & 77.1 & $-168.1^{\mathrm{i}}$ & -188.6 & -62.9 \\
\hline
\end{tabular}

a Only the fully dehydrogenated molecules are shown. Details are given in Tables S5 and S10. ${ }^{\mathrm{b}}$ For the fully-dehydrogenated molecules. Data from Table 1. ' For the fully-hydrogenated molecules. Vaporization enthalpies estimated using group-contributions listed in Table S6. ${ }^{\mathrm{d}}$ Calculated directly from $\mathrm{H}_{298}$-values of the hydrogenation reaction participants. ${ }^{\mathrm{e}}$ Calculated according to Equation (6). The uncertainty is assessed to be on the level of $\pm 3.5 \mathrm{~kJ} \cdot \mathrm{mol}^{-1}$. ${ }^{\mathrm{f}}$ Reaction enthalpy per mole of hydrogen in $\mathrm{kJ} \cdot \mathrm{mol}^{-1} / \mathrm{H}_{2} .{ }^{\mathrm{g}}$ From ref. [53]. ${ }^{\mathrm{h}}$ From ref. [55]. ${ }^{\text {i }}$ Calculated by G3MP2 according to the Hess's Law applied to reaction: 2,6-di-tert-butyl-pyridine + benzene = 2-tert-butyl-pyridine + tert-butyl-benzene. Data for tert-butyl-benzene were taken from [54]. 
Table 9. Reaction enthalpy of hydrogenation/dehydrogenation of aniline derivatives, at $T=298 \mathrm{~K}\left(p^{\circ}=0.1 \mathrm{MPa}\right)$ in $\mathrm{kJ} \cdot \mathrm{mol}^{-1}$.

\begin{tabular}{|c|c|c|c|c|c|}
\hline Compounds $^{a}$ & $\Delta_{1}^{\mathrm{g}} H_{\mathrm{m}}^{\mathrm{o}} \mathrm{b}$ & $\Delta_{1}^{\mathrm{g}} H_{\mathrm{m}}^{\mathrm{o}} \mathrm{c}$ & $\Delta_{\mathrm{r}} H_{\mathrm{m}}^{\mathrm{o}}(\mathrm{g}) \mathrm{G}_{4}{ }^{\mathrm{d}}$ & $\Delta_{\mathrm{r}} H_{\mathrm{m}}^{\mathrm{o}}(\mathrm{liq}) \mathrm{G}_{4} \mathrm{e}$ & $\Delta_{\mathrm{r}} H_{\mathrm{m}}^{\mathrm{o}} / \mathrm{H}_{2}{ }^{\mathrm{f}}$ \\
\hline aniline & 55.8 & 43.9 & -185.0 & -173.1 & -57.7 \\
\hline $\begin{array}{c}\mathrm{N}- \\
\text { methylaniline }\end{array}$ & 55.0 & 46.4 & -183.0 & -174.4 & -58.1 \\
\hline $\begin{array}{c}\mathrm{N}, \mathrm{N}- \\
\text { dimethylaniline }\end{array}$ & 54.0 & 45.6 & -188.6 & -180.2 & -60.1 \\
\hline $\begin{array}{c}\mathrm{N}, \mathrm{N}- \\
\text { diphenylamine }\end{array}$ & 79.0 & 64.1 & $-386.6^{\mathrm{i}}$ & -371.7 & -62.0 \\
\hline $\begin{array}{c}\text { tri- } \\
\text { phenylamine }\end{array}$ & $90.2^{g}$ & $77.0^{\mathrm{h}}$ & $-558.0^{i}$ & -571.2 & -63.5 \\
\hline
\end{tabular}

a Only the fully dehydrogenated molecules are shown. Details are given in Tables S5 and S11. ${ }^{\mathrm{b}}$ For the-fully dehydrogenated molecules. Data from Table 1. ${ }^{\mathrm{c}}$ For the fully-hydrogenated molecules. Data from ref. [47]. ${ }^{\mathrm{d}}$ Calculated directly from $\mathrm{H}_{298}$-values of the hydrogenation reaction participants. ${ }^{\mathrm{e}}$ Calculated according to Equation (6). The uncertainty is assessed to be on the level of $\pm 3.5 \mathrm{~kJ} . \mathrm{mol}^{-1}$. ${ }^{\mathrm{f}}$ Reaction enthalpy per mole of hydrogen in $\mathrm{kJ} \cdot \mathrm{mol}^{-1} / \mathrm{H}_{2} .{ }^{\mathrm{g}}$ From Table $4 .{ }^{\mathrm{h}}$ Vaporization enthalpy was estimated using group-contributions listed in Table S6. ${ }^{\mathrm{i}}$ Calculated by G3MP2.

It has turned out, that a consequent methylation of the pyrazine ring (methyl, dimethyl, trimethyl, and tetramethyl) significantly reduce (see Table 6) the liquid phase reaction enthalpy (from $-178.7 \mathrm{~kJ} \cdot \mathrm{mol}^{-1}$ observed for unsubstituted pyrazine to $-145.4 \mathrm{~kJ} \cdot \mathrm{mol}^{-1}$ for tetramethylpyrazine). Surprisingly, the sterically hindered tert-butylpyrazine has hydrogenation enthalpy $\left(-175.8 \mathrm{~kJ} \cdot \mathrm{mol}^{-1}\right)$ comparable to the unsubstituted pyrazine, moreover the considerably more strained 2,6-di-tert-butylpyrazine also exhibit (see Table 6) substantial energetic level $\left(-156.1 \mathrm{~kJ} \cdot \mathrm{mol}^{-1}\right)$. This peculiarity of the sterically strained substituted pyrazines could be interesting for practical implementation in the LOHC technology.

Compared to the pyrazine ring, the quinoxaline ring has a hydrogen storage capacity $\left(5\right.$ mole $\mathrm{H}_{2}$ ) about 1.7 times greater, but this benefit is energetically covered by the 1.7 times larger (see Table 7) hydrogenation enthalpy of quinoxaline $\left(-299.7 \mathrm{~kJ} \cdot \mathrm{mol}^{-1}\right)$. The consequent methylation of the quinoxaline ring (methyl and dimethyl shown in Table 7) is similar to the effect on the pyrazine ring and causes a gradual decrease in the liquid phase reaction enthalpy (from $-299.7 \mathrm{~kJ} \cdot \mathrm{mol}^{-1}$ observed for unsubstituted quinoxaline to $-279.3 \mathrm{~kJ} \cdot \mathrm{mol}^{-1}$ for 2,3-dimethylquinoxaline). Displacement of methyl-substituents and nitrogen atoms on the quinoxaline aromatic rings (e.g., results for 2,3-dimethylquinoxaline and 2,6-dimethyl-1,5-naphthyridine are given in Table 7) is also not thermoneutral. Accordingly, the storage capacity $\left(7\right.$ mole $\left.\mathrm{H}_{2}\right)$ and hydrogenation enthalpy $\left(-434.3 \mathrm{~kJ} \cdot \mathrm{mol}^{-1}\right)$ of phenazine are significantly larger comparable to the unsubstituted pyrazine and quinoxaline.

Hydrogenation of pyridine and its derivatives (see Table 8) seems to be energetically equal (except for crowded 2-tert-butyl- and 2,6-di-tert-butyl-pyridine,) to analogous alkylpyrazines (see Table 6). The sterically hindered tert-butyl-pyridines exhibit not only the highest for the pyridine series hydrogenation enthalpies, but also 2,6-di-tert-butylpyridines with $\Delta_{\mathrm{r}} H_{\mathrm{m}}^{\mathrm{o}}(\mathrm{liq})_{\mathrm{G} 4}=-188.6 \mathrm{~kJ} \cdot \mathrm{mol}^{-1}$ is apparently a leader in the series of monoheterocyclic compounds shown in Tables 6 and 8 . 
Aniline derivatives (see Table 9) can be considered as unbeatable low-cost nitrogen containing LOHC. The liquid phase hydrogenation enthalpies of aniline $\left(-173.1 \mathrm{~kJ} \cdot \mathrm{mol}^{-1}\right)$, $\mathrm{N}$-methyl-aniline $\left(-174.4 \mathrm{~kJ} \cdot \mathrm{mol}^{-1}\right)$, and $\mathrm{N}, \mathrm{N}$-dimethyl-aniline $\left(-180.2 \mathrm{~kJ} \cdot \mathrm{mol}^{-1}\right)$ listed in Table 9 are apparently on the same level as those for pyrazine and methylpyrazine (see Table 6). For diphenylamine the hydrogen storage capacity of 6 mole $\mathrm{H}_{2}$ amounts the hydrogenation enthalpy $-371.7 \mathrm{~kJ} \cdot \mathrm{mol}^{-1}$. The increasing of hydrogen storage capacity up

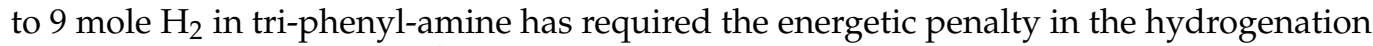
enthalpy of $-571.2 \mathrm{~kJ} \cdot \mathrm{mol}^{-1}$.

Chemical engineering of hydrogen storage frequently operates with a specific unity "reaction enthalpy per mole of hydrogen, $\mathrm{kJ} \cdot \mathrm{mol}^{-1} / \mathrm{H}_{2}$ " for reaction enthalpy of the hydrogenation/dehydrogenation process. Following this line, we have calculated (see Tables 6-9, last column) hydrogenation enthalpies of pyrazine, quinoxaline, pyridine, and aniline derivatives. Values of reaction enthalpy $-59.7 \mathrm{~kJ} \cdot \mathrm{mol}^{-1} / \mathrm{H}_{2}$ calculated for unsubstituted pyrazine, $-59.9 \mathrm{~kJ} \cdot \mathrm{mol}^{-1} / \mathrm{H}_{2}$ for unsubstituted quinoxaline, and $59.2 \mathrm{~kJ} \cdot \mathrm{mol}^{-1} / \mathrm{H}_{2}$ for hydrogenation of unsubstituted pyridine. Analysis of the reaction enthalpies per mole of hydrogen for miscellaneous LOHC candidates presented in Tables 6-9 has revealed that the values scatter in very narrow range between 52 and $63 \mathrm{~kJ} \cdot \mathrm{mol}^{-1} / \mathrm{H}_{2}$. These values are not significantly higher in comparison to N-ethyl-carbazole with $\Delta_{\mathrm{r}} H_{\mathrm{m}}^{\mathrm{o}}$ (liq) G4 $=-50.5 \mathrm{~kJ} \cdot \mathrm{mol}^{-1} / \mathrm{H}_{2}$ [2] (considered as the most acknowledged candidate from the $\mathrm{N}$-containing aromatics), as well as comparable with pure hydrocarbon LOHC such as commercially available thermofluids biphenyl $\left(-65.4 \mathrm{~kJ} \cdot \mathrm{mol}^{-1} / \mathrm{H}_{2}\right)[56]$, benzyltoluenes (Marlothem $\left.\mathrm{LH}^{\circledR}\right)$ and dibenzyltoluenes (Marlotherm $\left.\mathrm{SH}^{\circledR}\right)\left(-63.5\right.$ and $-65.4 \mathrm{~kJ} \cdot \mathrm{mol}^{-1} / \mathrm{H}_{2}$, respectively) [57].

\subsection{Thermodynamic Analysis of the Hydrogenation Process in the Gas Phase}

Quantification of energetics of the hydrogenation/dehydrogenation reactions is important part of the LOHC-technology optimization. However, the general thermodynamic analysis based on standard molar Gibbs energies, $\Delta_{\mathrm{r}} G_{\mathrm{m}}^{\mathrm{o}}$, provide direct access to the yield and the degree of conversion of the hydrogenation/dehydrogenation reactions. As it has been shown in previous section, the high-level composite QC methods are reliable for energetics of chemical reactions. Admittedly, the quantum chemical calculations for the $\Delta_{\mathrm{r}} G_{\mathrm{m}}^{\mathrm{o}}$, and especially for $K_{p}$ are very demanding. In order to test the ability of the G4 method to provide reliable $K_{p}$-values, we have calculated standard molar Gibbs energy of the well-known ethylbenzene dehydrogenation reaction with reliable experimental data [58]. As can be seen from result given in Table S12, the excellent agreement between theoretical and experimental $\Delta_{\mathrm{r}} G_{\mathrm{m}}^{\mathrm{o}}$ and $K_{p}$ values achieved at $298 \mathrm{~K}$ and $400 \mathrm{~K}$ provide confidence in results with G4 method calculations. Thus, in this work we used the G4 method for calculation of thermodynamic functions involved in Equation (2): the standard molar Gibbs energies, the standard molar enthalpies of formation, and the standard molar entropies of hydrogenation/dehydrogenation reactions of miscellaneous LOHC (see Tables 10 and 11).

Table 10. Thermodynamic analysis of pyrazine and trans-2,5-dimethylpyrazine hydrogenation reaction (according to Equation (1)), as calculated by the G4 method.

\begin{tabular}{ccccc}
\hline Compound & \multicolumn{2}{c}{ Pyrazine } & \multicolumn{2}{c}{ 2,5-Dimethylpyrazine } \\
\hline Thermodynamic Functions & $\mathbf{2 9 8 ~ K}$ & $\mathbf{4 0 0 ~ K}$ & $\mathbf{2 9 8 ~ K}$ & $\mathbf{4 0 0 ~ K}$ \\
\hline$\Delta_{\mathrm{r}} G_{\mathrm{m}}^{\mathrm{o}} / \mathrm{kJ} \cdot \mathrm{mol}^{-1}$ & -58.8 & -20.4 & -43.1 & -2.5 \\
$\Delta_{\mathrm{r}} H_{\mathrm{m}}^{\mathrm{o}} / \mathrm{kJ} \cdot \mathrm{mol}^{-1}$ & -168.7 & -174.3 & -159.5 & -165.3 \\
$\Delta_{\mathrm{r}} S_{\mathrm{m}}^{\mathrm{o}} / \mathrm{J} \cdot \mathrm{mol}^{-1} \cdot \mathrm{K}^{-1}$ & -368.7 & -384.8 & -390.4 & -407.1 \\
$K_{p}{ }^{\mathrm{a}}$ & $2.0 \times 10^{10}$ & $4.6 \times 10^{2}$ & $3.6 \times 10^{7}$ & 2.1 \\
$\left(\frac{p_{\text {pyrazine }} \times p_{\mathrm{H} 2}}{p_{\text {piperazine }}}\right)^{\mathrm{b}}$ & 5.9 & 2.7 & 2.3 & 1.2 \\
$K_{a}{ }^{\mathrm{c}}$ & $1.2 \times 10^{11}$ & $1.2 \times 10^{3}$ & $8.3 \times 10^{7}$ & 2.5 \\
\hline
\end{tabular}

${ }^{a}$ Calculated according to Equation (2). Details are given in Table S13. ${ }^{\mathrm{b}}$ Vapor pressures at $298 \mathrm{~K}$ and $400 \mathrm{~K}$ are given in Table S14. ${ }^{c}$ Calculated according to Equation (3). 
Table 11. Thermodynamic analysis of the hydrogenation of LOHC candidates in the gas phase (at $298 \mathrm{~K}$ and $p^{\circ}=0.1 \mathrm{MPa}$ ) calculated using G4 method, thermodynamic equilibrium constant $K_{p}$ at $298 \mathrm{~K}$.

\begin{tabular}{|c|c|c|c|c|c|}
\hline Compounds & $\Delta_{\mathrm{r}} \mathrm{G}_{\mathrm{m}}^{\mathrm{o}}(\mathrm{g})$ & $\Delta_{\mathrm{r}} H_{\mathrm{m}}^{\mathrm{o}}(\mathrm{g})$ & $\Delta_{\mathrm{r}} S_{\mathrm{m}}^{\mathrm{o}}(\mathrm{g})$ & $K_{p}$ & $\mathrm{~T}_{\text {eq }}$ \\
\hline & $\mathrm{kJ} \cdot \mathrm{mol}^{-1}$ & $\mathrm{~kJ} \cdot \mathrm{mol}^{-1}$ & $\mathrm{~J} \cdot \mathrm{mol}^{-1} \cdot \mathrm{K}^{-1}$ & & $\mathbf{K}$ \\
\hline \multicolumn{6}{|c|}{ Pyrazines } \\
\hline \multirow{10}{*}{$\begin{array}{c}\text { pyrazine } \\
\text { methylpyrazine } \\
\text { 2,3-dimethylpyrazine } \\
\text { 2,5-dimethylpyrazine } \\
\text { trimethylpyrazine } \\
\text { tetramethylpyrazine } \\
\text { tert-butylpyrazine } \\
\text { 2,6-di-tert- } \\
\text { butylpyrazine } \\
\text { triazine }\end{array}$} & -58.8 & -168.7 & -368.7 & $2.0 \times 10^{10}$ & 458 \\
\hline & -52.9 & -166.3 & -380.5 & $1.8 \times 10^{9}$ & 437 \\
\hline & -45.9 & -157.8 & -375.3 & $1.1 \times 10^{8}$ & 420 \\
\hline & -43.1 & -159.5 & -390.4 & $8.3 \times 10^{7}$ & 408 \\
\hline & -38.3 & -153.8 & -387.5 & $5.1 \times 10^{6}$ & 397 \\
\hline & -35.0 & -149.4 & -383.6 & $1.3 \times 10^{6}$ & 389 \\
\hline & -46.6 & -159.8 & -379.8 & $1.5 \times 10^{8}$ & 421 \\
\hline & -20.4 & -132.3 & -375.4 & $3.7 \times 10^{3}$ & 352 \\
\hline & -18.3 & -129.0 & -371.3 & $1.6 \times 10^{3}$ & 347 \\
\hline & \multicolumn{5}{|c|}{ Pyridines } \\
\hline \multirow{7}{*}{$\begin{array}{c}\text { pyridine } \\
\text { 2-methylpyridine } \\
\text { 4-methylpyridine } \\
\text { 2,6-dimethylpyridine } \\
\text { 4-tert-butyl-pyperidine } \\
\text { 2,6-di-tert-butyl- } \\
\text { pyperidine }\end{array}$} & -69.2 & -178.6 & -367.0 & $1.3 \times 10^{12}$ & 487 \\
\hline & -61.4 & -174.7 & -380.2 & $5.7 \times 10^{10}$ & 459 \\
\hline & -61.6 & -175.1 & -380.7 & $6.2 \times 10^{10}$ & 460 \\
\hline & -52.0 & -170.9 & -398.7 & $1.3 \times 10^{9}$ & 429 \\
\hline & -61.4 & -170.0 & -364.1 & $5.8 \times 10^{10}$ & 467 \\
\hline & -55.8 & -168.1 & -376.5 & $5.9 \times 10^{9}$ & 446 \\
\hline & \multicolumn{5}{|c|}{ Anilines } \\
\hline aniline & -75.5 & -185.0 & -367.6 & $1.6 \times 10^{13}$ & 503 \\
\hline N-methyl-aniline & -73.5 & -183.0 & -367.3 & $7.5 \times 10^{12}$ & 498 \\
\hline $\mathrm{N}, \mathrm{N}$-dimethyl-aniline & -76.5 & -188.6 & -376.2 & $2.5 \times 10^{13}$ & 501 \\
\hline diphenylamine & -166.3 & -386.6 & -739.0 & $1.3 \times 10^{29}$ & 523 \\
\hline triphenylamine & -224.6 & -558.0 & -1118.2 & $2.2 \times 10^{39}$ & 499 \\
\hline
\end{tabular}

For practical purpose, it has been reasonable to perform thermodynamic analysis of hydrogenation/dehydrogenation reactions at least at two significantly different temperatures. We selected the acknowledged reference temperature $T=298 \mathrm{~K}$ and practically relevant $T=400 \mathrm{~K}$. The latter temperature represents an acceptable level for the on-board energy delivery on vehicles. Calculations at the reference temperature $T=298 \mathrm{~K}$ are practically irrelevant, but they help to assess the trend of the equilibrium constants $K_{p}$ temperature dependences.

The theoretical gas-phase thermodynamic data for hydrogenation of pyrazine and 2,5-dimethylpyrazine, including chemical equilibrium constants $K_{p}$ at both temperatures are collected in Tables 10 and S13. It is obvious, that the equilibrium of the hydrogenation/dehydrogenation reactions at room temperatures is completely shifted to the left side (i.e., to the starting molecule), but the position of equilibrium is strongly temperature dependent and, already at $400 \mathrm{~K}$, the dehydrogenation reactions become more thermodynamically favorable.

Thermodynamic analysis of the hydrogenation reactions of miscellaneous LOHC candidates in the gas phase calculated using G4 method is summarized in Table 11. Taking into account reversibility of the hydrogenation/dehydrogenation processes, the thermodynamic functions $\Delta_{\mathrm{r}} G_{\mathrm{m}}^{\mathrm{o}}(\mathrm{g}), \Delta_{\mathrm{r}} H_{\mathrm{m}}^{\mathrm{o}}(\mathrm{g})$, and $\Delta_{\mathrm{r}} S_{\mathrm{m}}^{\mathrm{o}}(\mathrm{g})$ given in Table 11 for the hydrogenation reaction will get the opposite sign for the dehydrogenation reaction. Results collected in Table 11 help to reveal that hydrogenation reactions are definitely "driven by enthalpy". Indeed, let us compare thermodynamic data obtained for reactions which involve methylpyrazine and tetramethylpyrazine. Both reactions exhibit quite similar reaction entropies $\Delta_{\mathrm{r}} S_{\mathrm{m}}^{\mathrm{o}}(\mathrm{g})$ : $-380.5 \mathrm{~J} \cdot \mathrm{mol}^{-1} \cdot \mathrm{K}^{-1}$ for methylpyrazine and $-383.6 \mathrm{~J} \cdot \mathrm{mol}^{-1} \cdot \mathrm{K}^{-1}$ for tetramethylpyrazine, although the $\Delta_{\mathrm{r}} H_{\mathrm{m}}^{\mathrm{o}}(\mathrm{g})$-values are different by only $16.9 \mathrm{~kJ} \cdot \mathrm{mol}^{-1}\left(-166.3 \mathrm{~kJ} \cdot \mathrm{mol}^{-1}\right.$ for methylpyrazine and $-149.4 \mathrm{~kJ} \cdot \mathrm{mol}^{-1}$ for tetramethylpyrazine). Nevertheless, this difference is quite decisive for the level of the gas-phase equilibrium constant $K_{p}: 1.8 \times 10^{9}$ 
for methylpyrazine and $1.3 \times 10^{6}$ for tetramethylpyrazine. The similar trend was observed within all three series of the LOHC candidates-pyrazine, pyridine, and aniline derivatives. This finding has reinforced importance of precise studies of energetics of the hydrogenation/dehydrogenation process in order to select most suitable LOHC candidate and optimize conditions for application.

Equilibrium of hydrogenation/dehydrogenation processes exhibit many similarities with polymerization/depolymerization processes, because the enthalpy also drives polymerizations [59]. According to the Gibbs free energy equation (Equation (2)), the entropy term is negative. Thus, at low temperatures, the enthalpy term dominates over the entropy term, which allows hydrogenation or polymerization to occur. In polymer chemistry, ceiling temperature $T_{\mathrm{c}}$ is a practical measure of the trend of a polymer to revert to the starting monomers. At the ceiling temperature, the enthalpy term $\Delta_{\mathrm{r}} H_{\mathrm{m}}^{\mathrm{o}}$ and the entropy term $T \times \Delta_{\mathrm{r}} S_{\mathrm{m}}^{\mathrm{o}}$ are equal. Above the ceiling temperature, the depolymerization begins to be thermodynamically favorable. At equilibrium $\Delta_{\mathrm{r}} G_{\mathrm{m}}^{\mathrm{o}}=0$ and we can re-arrange Equation (2) to get expression $\Delta_{\mathrm{r}} H_{\mathrm{m}}^{\mathrm{o}}=T \times \Delta_{\mathrm{r}} S_{\mathrm{m}}^{\mathrm{o}}$ leading to the definition of the ceiling temperature as the ratio $\left(T_{\mathrm{c}}=\Delta_{\mathrm{r}} H_{\mathrm{m}}^{\mathrm{o}} / \Delta_{\mathrm{r}} S_{\mathrm{m}}^{\mathrm{o}}\right)$. Using this analogy with the polymerization/depolymerization processes it is practically important to define an equilibrium temperature $T_{\text {eq }}$, which is able to imply the reverse of thermodynamic feasibility from hydrogenation to dehydrogenation trend:

$$
T_{\mathrm{eq}}=\frac{\Delta_{\mathrm{r}} H_{\mathrm{m}}^{\mathrm{o}}}{\Delta_{\mathrm{r}} S_{\mathrm{m}}^{\mathrm{o}}}
$$

This temperature could be valuable indicator for design and selection of effective LOHC. This equilibrium temperature is desired to be not too low for the hydrogenation step in order to keep acceptable reaction rates. At the same time, for the dehydrogenation step the $T_{\text {eq }}$ is expected to be not too high, but sufficient for a good level of conversion and selectivity. Results for $T_{\text {eq }}$ calculations according to Equation (12) for pyrazine, pyridine, and aniline derivatives are given in Table 11, last column. It is apparent from this table that alkyl-pyrazines exhibit the lowest equilibrium temperatures (except for unsubstituted pyrazine and methylpyrazine) at the level of $400 \mathrm{~K}$. The pyridine derivatives show the $T_{\text {eq }}$-values around $450 \mathrm{~K}$ and for aniline derivatives the highest $T_{\text {eq }}$-values around $500 \mathrm{~K}$ are required. Thus, the pyrazine derivatives appear to be significantly more suitable LOHC candidates compared to the aniline derivatives. A short, but important, comment on calculations according to Equation (12) have to be done. All $T_{\text {eq }}$ calculations in Table 11 have been performed by using thermodynamic functions referenced to $298 \mathrm{~K}$. However, the choice of the reference temperature is generally irrelevant for this type of calculations. To set an example, for hydrogenation/dehydrogenation of 2,5-dimethylpyrazine the value $T_{\mathrm{eq}}=408 \mathrm{~K}$ was calculated in Table 11 . However, by using thermodynamic functions for this compound given in Table 10 and referenced to $400 \mathrm{~K}$, the value $T_{\text {eq }}=406 \mathrm{~K}$ was estimated. The difference is marginal for theoretical and practical applications and it means that quantum-chemical calculations can be successfully applied for characterization and selection of efficient LOHC candidates.

\subsection{Thermodynamic Equilibrium Constants of the Hydrogenation/Dehydrogenation Reactions from Quantum-Chemical Calculations}

From a practical point of view, the most interesting thermodynamic result is the liquid phase equilibrium constant $K_{a}$. This constant provides preliminary information not only about the feasibility of the chemical reaction according to the Gibbs energy equation:

$$
\Delta_{\mathrm{r}} G_{\mathrm{m}}^{\mathrm{o}}(\mathrm{liq})=-R T \ln K_{a}
$$

However, it is also important to assess the expected theoretical concentrations of the reaction participants. The liquid phase equilibrium constant $K_{a}$ of the hydrogenation/dehydrogenation is related to the gas phase thermodynamic equilibrium constant, $K_{p}$, by Equation (3) (related exemplary to reactions 1 and 11, for the sake of brevity). Auxiliary data on vapor pressures at $298 \mathrm{~K}$ and $400 \mathrm{~K}$ are given in Table S14. Saturated vapor pres- 
sures for the 2,5-dimethylpyrazine and trans-2,5-dimethyl-piperazine are available in the literature (see Table S14). Using the theoretical $K_{p}$ calculated with help of the G4-method and presented in Table 10, the liquid phase thermodynamic equilibrium constant $K_{a}$ was calculated. Values of the liquid phase equilibrium constants for reaction hydrogenation of 2,5-dimethylpyrazine to trans-2,5-dimethyl-piperazine: very large $K_{a}=8.3 \times 10^{7}$ at $298 \mathrm{~K}$ and very small $K_{a}=2.5$ at $400 \mathrm{~K}$ indicate sufficient thermodynamic feasibility for the hydrogenation/dehydrogenation reversible process. This theoretical conclusion is in agreement with the practical observation for this reaction. Indeed, a new system for hydrogen storage based on the reversible interconversion between 2,5-dimethylpyrazine and 2,5-dimethylpiperazine by hydrogenation at $383 \mathrm{~K}$ and dehydrogenation at $411 \mathrm{~K}$ catalyzed by an iridium complex has been reported just recently [60]. Reversible and repetitive transformations between 2,5-dimethylpyrazine and 2,5-dimethylpiperazine, accompanied by the uptake and release of three equivalents of hydrogen was repeated almost quantitatively at least four times without any loss of efficiency [60].

As can be seen in Table 10, the contribution from multiplication of pressures ( $p_{\text {pyrazine }} \times$ $\left.p_{\mathrm{H} 2} / p_{\text {piperazine }}\right)$ in Equation (3) is altering from 1.2 to 5.9 depending on the structure of reaction participants and reaction temperature. Nevertheless, this $p$-factor is hardly decisive for the general level of the $K_{a}$ even at $400 \mathrm{~K}$ as compared to the level of $K_{p}$ (see Table 10) derived by the G4 method. This observation is of utmost importance for the successful application of quantum chemical methods to the advanced screening of suitable LOHC candidates. Indeed, even taking into account the use of time-consuming and resource-intensive high-level $\mathrm{G}^{*}$ methods, the in silico assessment of reliable $K_{p}$-values for any hydrogenation/dehydrogenation reaction at any desired temperature opens the window of the possibility of reducing the experimental thermochemical effort and performing the general computational search for promising LOHC structures suitable for various transportation, household, etc. niche applications.

\section{Conclusions}

In summary, the in silico procedure, which is based on the combination of experimental and quantum-chemical results, can be practically applied to evaluate reaction parameters and yields for a wide range of hydrogenation/dehydrogenation reactions, that are involved in the LOHC-technologies. With this quantum chemical tool, the tempo of the reliable search for suitable candidates will accelerate dramatically, leading to the design and development of efficient materials for various niche applications.

Supplementary Materials: The following are available online at https://www.mdpi.com/2673 $-4141 / 2 / 1 / 6 /$ s1, Figure S1: Temperature dependence of vapor pressures over the 2,3-di-methylquinoxaline, Figure S2: Comparison of vaporization enthalpies of pyrazines, quinoxalines, and benzenes. Table S1: Provenance, purity, methods of purification and analysis of chemicals used in this work, Table S2: Results of transpiration method for quinoxaline derivatives, Table S3: Compilation of data on molar heat capacities, Table S4: Compilation of enthalpies of vaporization/sublimation for pyrazine derivatives derived from the data available in the literature, Table S5: Thermochemical data at $T=298.15 \mathrm{~K}\left(p^{\circ}=0.1 \mathrm{MPa}\right)$ for the pyridine and aniline derivatives, Table S6: Group-additivity values for calculation of enthalpies of vaporization of alkanes and amines. Table S7: Experimental and estimated by group-additivity vaporization enthalpies at $\mathrm{T}=298.15 \mathrm{~K}$ for cyclohexanamines Table S8: Reaction enthalpy of hydrogenation/dehydrogenation of pyrazine derivatives, Table S9: Reaction enthalpy of hydrogenation/dehydrogenation of quinoxaline derivatives, Table S10: Reaction enthalpy of hydrogenation/dehydrogenation of pyridine derivatives, Table S11: Reaction enthalpy of hydrogenation/dehydrogenation of aniline derivatives, Table S12: Thermodynamic analysis of the dehydrogenation of ethylbenzene in the gas phase calculated using G4 method and thermodynamic equilibrium constants, Table S13: Thermodynamic analysis of the hydrogenation of 2,5-di-methylpyrazine in the gas phase calculated using G4 method and thermodynamic equilibrium constants, Table S14: Experimental vapor pressures of hydrogenation/dehydrogenation reactions participants used for adjustment of the theoretical thermodynamic equilibrium constants. 
Author Contributions: Conceptualization, S.P.V.; methodology, S.P.V.; validation, S.P.V., R.S., and A.A.P.; formal analysis, S.P.V., R.S. and A.A.P.; investigation, V.N.E.; writing-original draft preparation, S.P.V., R.S. and A.A.P.; writing-review and editing, S.P.V., R.S. and A.A.P.; supervision, S.P.V.; project administration, S.P.V.; funding acquisition, S.P.V. All authors have read and agreed to the published version of the manuscript.

Funding: This research was funded by the Government of Russian Federation (decree no. 220 of 9 April 2010), agreement no. 14.Z50.31.0038. The RS was funded by from the German Science Foundation (DFG) in the frame of the priority program SPP 1807 and in the frame of the priority program SPP 1708 “Material Synthesis Near Room Temperature” (grant VE 265-14/2 to SPV)

Institutional Review Board Statement: Not applicable.

Informed Consent Statement: Not applicable.

Data Availability Statement: Not applicable.

Conflicts of Interest: The authors declare no conflict of interest.

\section{References}

1. Preuster, P.; Papp, C.; Wasserscheid, P. Liquid Organic Hydrogen Carriers (LOHCs): Toward a Hydrogen-free Hydrogen Economy. Acc. Chem. Res. 2017, 50, 74-85. [CrossRef] [PubMed]

2. Verevkin, S.P.; Emel'yanenko, V.N.; Heintz, A.; Stark, K.; Arlt, W. Liquid Organic Hydrogen Carriers: An Upcoming Alternative to Conventional Technologies. Thermochemical Studies. Ind. Eng. Chem. Res. 2012, 51, 12150-12153. [CrossRef]

3. Stark, K.; Emel'yanenko, V.N.; Zhabina, A.A.; Varfolomeev, M.A.; Verevkin, S.P.; Müller, K.; Arlt, W. Liquid Organic Hydrogen Carriers: Thermophysical and Thermochemical Studies of Carbazole Partly and Fully Hydrogenated Derivatives. Ind. Eng. Chem. Res. 2015, 54, 7953-7966. [CrossRef]

4. Emel'yanenko, V.N.; Varfolomeev, M.A.; Verevkin, S.P.; Stark, K.; Müller, K.; Müller, M.; Bösmann, A.; Wasserscheid, P.; Arlt, W. Hydrogen Storage: Thermochemical Studies of N-Alkylcarbazoles and Their Derivatives as a Potential Liquid Organic Hydrogen Carriers. J. Phys. Chem. C 2015, 119, 26381-26389. [CrossRef]

5. Hu, P.; Fogler, E.; Diskin-Posner, Y.; Iron, M.A.; Milstein, D. A novel liquid organic hydrogen carrier system based on catalytic peptide formation and hydrogenation. Nat. Commun. 2015, 6, 6859. [CrossRef]

6. Benson, S.W. Thermochemical Kinetics: Methods for the Estimation of Thermochemical Data and Rate Parameters; John Wiley \& Sons, Inc.: New York, NY, USA, 1968.

7. Domalski, E.S.; Hearing, E.D. Estimation of the thermodynamic properties of C-H-N-O-S-X compounds at 298K. J. Phys. Chem. Ref. Data 1993, 22, 805-1159. [CrossRef]

8. Verevkin, S.P. Improved benson's increments for the estimation of the standard enthalpies of formation and enthalpies of vaporization of alkyl ethers, acetals, ketals, and orthoesters. J. Chem. Eng. Data 2002, 47, 1071-1097. [CrossRef]

9. Verevkin, S.P.; Emel'yanenko, V.N.; Diky, V.; Muzny, C.D.; Chirico, R.D.; Frenkel, M. New group contribution approach to thermochemical properties of organic compounds: Hydrocarbons and oxygen containing compounds. J. Phys. Chem. Ref. Data 2013, 42, 033102. [CrossRef]

10. Verevkin, S.P.; Emel'yanenko, V.N. Transpiration method: Vapor pressures and enthalpies of vaporization of some low-boiling esters. Fluid Phase Equilib. 2008, 266, 64-75. [CrossRef]

11. Verevkin, S.P.; Sazonova, A.Y.; Emel'yanenko, V.N.; Zaitsau, D.H.; Varfolomeev, M.A.; Solomonov, B.N.; Zherikova, K.V. Thermochemistry of halogen-substituted methylbenzenes. J. Chem. Eng. Data 2015, 60, 89-103. [CrossRef]

12. Emel'yanenko, V.N.; Verevkin, S.P. Benchmark thermodynamic properties of 1, 3-propanediol. Comprehensive experimental and theoretical study. J. Chem. Thermodyn. 2015, 85, 111-119. [CrossRef]

13. Emel'yanenko, V.N.; Zaitsau, D.H.; Shoifet, E.; Meurer, F.; Verevkin, S.P.; Schick, C.; Held, C. Benchmark thermochemistry for biologically relevant adenine and cytosine. A combined experimental and theoretical Study. J. Phys. Chem. A 2015, 119, 9680-9691. [CrossRef]

14. Frisch, M.J.; Truck, G.W.; Schlegel, H.B.; Scuseria, G.E.; Robb, M.A.; Cheemeseman, G.; Scalmani, G.; Barone, V.; Mennucci, B.; Petersson, G.A.; et al. Gaussian 09; revision D.01; Gaussian Inc.: Wallingford, CT, USA, 2016.

15. Allinger, N.L.; Yuh, Y.H.; Lii, J.H. Molecular mechanics: The MM3 force field for hydrocarbons. J. Am. Chem. Soc. 1989, 111, 8551-8566. [CrossRef]

16. Petersson, G.A.; Bennett, A.; Tensfeldt, T.G.; Al-Laham, M.A.; Shirley, W.A.; Mantzaris, J. A complete basis set model chemistry I: The total energies of closed-shell atoms and hydrides of the first-row elements. J. Chem. Phys. 1988, 89, 2193-2218. [CrossRef]

17. Curtiss, L.A.; Redfern, P.C.; Raghavachari, K. Gaussian-4 theory. J. Chem. Phys. 2007, 126, 84108-84112. [CrossRef]

18. Curtiss, L.A.; Redfern, P.C.; Raghavachari, K.; Rassolov, V.; Pople, J.A. Gaussian-3 theory using reduced Möller-Plesset order. J. Chem. Phys. 1999, 110, 4703-4709. [CrossRef]

19. Verevkin, S.P.; Emel'yanenko, V.N.; Notario, R.; Roux, M.V.; Chickos, J.S.; Liebman, J.F. Rediscovering the wheel: Thermochemical analysis of energetics of the aromatic diazines. J. Phys. Chem. Lett. 2012, 3, 3454-3459. [CrossRef] [PubMed] 
20. Müller, K.; Vçlkl, J.; Arlt, W. Thermodynamic evaluation of potential organic hydrogen. Energy Technol. 2013, 1, 20-24. [CrossRef]

21. Emel'yanenko, V.N.; Zaitseva, K.V.; Agapito, F.; Simões, J.A.M.; Verevkin, S.P. Benchmark thermodynamic properties of methylanisoles: Experimental and theoretical study. J. Chem. Thermodyn. 2015, 85, 155. [CrossRef]

22. Verevkin, S.P. Pure Component Phase Changes Liquid and Gas. In Experimental Thermodynamics: Measurement of the Thermodynamic Properties of Multiple Phases; Weir, R.D., De Loos, T.W., Eds.; Elsevier: Amsterdam, The Netherlands, 2005; Volume 7, pp. 6-30.

23. Verevkin, S.P.; Emel'yanenko, V.N.; Pimerzin, A.A.; Vishnevskaya, E.E. Thermodynamic analysis of strain in the five-membered oxygen and nitrogen heterocyclic compounds. J. Phys. Chem. A 2011, 115, 1992-2004. [CrossRef]

24. Verevkin, S.P.; Emel'yanenko VNPimerzin, A.A.; Vishnevskaya, E.E. Thermodynamic analysis of strain in heteroatom derivatives of indene. J. Phys. Chem. A 2011, 115, 12271-12279. [CrossRef]

25. Wheeler, S.E.; Houk, K.N.; Schleyer, P.V.R.; Allen, W.D. A hierarchy of homodesmotic reactions for thermochemistry. J. Am. Chem. Soc. 2009, 131, 2547-2560. [CrossRef]

26. Ribeiro da Silva, M.A.V.; Matos, M.A.R. Thermochemical and theoretical studies of some benzodiazines. J. Chem. Soc. Faraday Trans. 1995, 91, 1907-1910. [CrossRef]

27. Lipkind, D.; Chickos, J.S.; Liebman, J.F. Study of the anomalous thermochemical behavior of 1, 2-diazines by correlation-gas chromatography. J. Chem. Eng. Data 2010, 55, 1628-1635. [CrossRef]

28. Ribeiro da Silva, M.A.V.; Morais, V.M.F.; Matos, M.A.R.; Rio, C.M.A.; Piedade, G.M.G.S. Thermochemical and theoretical study of some methyldiazines. Struct. Chem. 1996, 7, 329-336. [CrossRef]

29. Monte, M.J.S.; Hillesheim, D.M. Thermodynamic study on the sublimation of six substituted quinoxalines. J. Chem. Eng. Data 2000, 45, 1088-1092. [CrossRef]

30. Chirico, R.D.; Kazakov, A.F.; Steele, W.V. Thermodynamic properties of three-ring aza-aromatics. 1. Experimental results for phenazine and acridine, and mutual validation of experiments and computational methods. J. Chem. Thermodyn. 2010, 42, 571-580. [CrossRef]

31. Sabbah, R.; Pemenzi, O. Energetics of intermolecular bonds in the three diazines: Phthalazine, quinazoline and quinoxaline. Comptes Rendus Acad. Sci. Ser. II 1993, 317, 575-583.

32. McEachern, D.M.; Sandoval, O.; Iniguez, J.C. Vapor pressures, derived enthalpies of sublimation, enthalpies of fusion, and resonance energies of acridine and phenazine. J. Chem. Thermodyn. 1975, 7, 299-306. [CrossRef]

33. Bystrom, K. The stabilization energy of 1, 3, 5-triazine derived from measurements of the enthalpies of combustion and sublimation. J. Chem. Thermodyn. 1982, 14, 865-870. [CrossRef]

34. Briels, W.J.; van Miltenburg, J.C. s-Triazine: Heat capacities between 130 and $380 \mathrm{~K}$, the solid state transition, and the enthalpy of melting. J. Chem. Phys. 1979, 70, 1064-1066. [CrossRef]

35. Surov, A.O.; Perlovich, G.L.; Emel'yanenko, V.N.; Verevkin, S.P. Thermochemistry of Drugs. Experimental and first-principles study of fenamates. J. Chem. Eng. Data 2011, 56, 4325-4332. [CrossRef]

36. Steele, W.V. The standard enthalpies of formation of the triphenyl compounds of the Group V elements. 1. Triphenylamine and the Ph-N bond-dissociation energy. J. Chem. Thermodyn. 1978, 10, 441-444. [CrossRef]

37. Chickos, J.S.; Acree, W.E. Enthalpies of vaporization of organic and organometallic compounds, 1880-2002. J. Phys. Chem. Ref. Data 2003, 32, 519-878. [CrossRef]

38. Verevkin, S.P.; Heintz, A. Determination of vaporization enthalpies of the branched esters from correlation gas-chromatography and transpiration methods. J. Chem. Eng. Data 1999, 44, 1240-1244. [CrossRef]

39. Wong, J.M.; Bernhard, R.A. Effect of nitrogen source on pyrazine formation. J. Agric. Food Chem. 1988, 36, 123-129. [CrossRef]

40. Emel'yanenko, V.N.; Verevkin, S.P.; Koutek, B.; Doubsky, J. Vapor pressures and enthalpies of vaporization of a series of the linear aliphatic nitriles. J. Chem. Thermodyn. 2005, 37, 73-81. [CrossRef]

41. Verevkin, S.P.; Krasnykh, E.L.; Vasiltsova, T.V.; Heintz, A. Determination of vaporization enthalpies of the branched ethers from transpiration and correlation gas-chromatography methods. J. Chem. Eng. Data 2003, 48, 591-599. [CrossRef]

42. Verevkin, S.P. Vapour pressures and enthalpies of vaporization of a series of the linear n-alkyl-benzenes. J. Chem. Thermodyn. 2006, 38, 1111-1123. [CrossRef]

43. Ribeiro da Silva, M.D.M.C.; Cabral, J.I.T.A.; Givens, C.; Keown, S.; Acree, W.E., Jr. Thermochemical study of three dimethylpyrazine derivatives. J. Therm. Anal. Calorim. 2008, 92, 73-78. [CrossRef]

44. Morais, V.M.F.; Miranda, M.S.; Matos, M.; Agostinha, R. Thermochemical study of the ethylpyridine and ethylpyrazine isomers. Org. Biomol. Chem. 2003, 1, 4329-4712. [CrossRef] [PubMed]

45. Verevkin, S.P. Thermochemistry of amines: Strain in six-memberd rings from experimental standard molar enthalpies of formation of morpholines and piperazines. J. Chem. Thermodyn. 1998, 30, 1069-1079. [CrossRef]

46. Steele, W.V.; Chirico, R.D.; Knipmeyer, S.E.; Nguyen, A.; Smith, N.K. Thermodynamic properties and ideal-gas enthalpies of formation for carbonate, piperazine, hexachloroprop-1-ene, tetrakis(dimethylamino) ethylene, $\mathrm{N}, \mathrm{N}^{\prime}$-Bis(2hydroxyethyl)ethylenediamine, and 1, 2, 4-triazolo[1, 5-a]pyrimidine. J. Chem. Eng. Data 1997, 42, 1037-1052. [CrossRef]

47. Verevkin, S.P.; Emel'yanenko, V.N. Thermodynamic properties of cyclohexanamines: Experimental and theoretical study. Thermochim. Acta 2015, 608, 40-48. [CrossRef]

48. Verevkin, S.P. Thermochemistry of amines: Experimental standard molar enthalpies of formation of $\mathrm{N}$-alkylated piperidines. Struct Chem. 1998, 9, 113-118. [CrossRef] 
49. Efimova, A.A.; Emel'yanenko, V.N.; Verevkin, S.P.; Chernyak, Y. Vapour pressure and enthalpy of vaporization of aliphatic poly-amines. J. Chem. Thermodyn. 2010, 42, 330-346. [CrossRef]

50. Pozdeev, V.A.; Verevkin, S.P. Vapour pressure and enthalpy of vaporization of linear aliphatic alkanediamines. J. Chem. Thermodyn. 2011, 43, 1791-1799.

51. Verevkin, S.P.; Emel'yanenko, V.N.; Garist, I.V. Benchmark thermodynamic properties ofalkanediamines: Experimental and theoretical study. J. Chem. Thermodyn. 2015, 87, 34-42. [CrossRef]

52. Verevkin, S.P.; Emel'yanenko, V.N.; Pozdeev, V.A.; Diky, V.; Chirico, R.; Kroenlein, K. Thermodynamic properties of N-methylsubstituted ethane-1, 2-diamines: Experimental and computational study. J. Chem. Eng. Data 2016, 61, 1811-1820. [CrossRef]

53. Ribeiro da Silva, M.A.V.; Cabral, J.I.T.A.; Gomes, P.; Gomes, J.R.B. Combined experimental and computational study of the thermochemistry of methylpiperidines. J. Org. Chem. 2006, 71, 3677-3685. [CrossRef]

54. Verevkin, S.P.; Kozlova, S.A.; Emel'yanenko, V.N.; Goodrich, P.; Hardacre, C. Thermochemistry of ionic liquid-catalysed reactions. Experimental and theoretical study of chemical equilibria of isomerisation and transalkylation of tert-butyl-benzenes. J. Phys. Chem. A 2008, 112, 11273-11282. [CrossRef]

55. Good, W.D. Enthalpies of combustion of nine organic nitrogen compounds related to petroleum. J. Chem. Eng. Data 1972, 17, 28-31. [CrossRef]

56. Zaitsau, D.H.; Emel'yanenko, V.N.; AAPimerzin, A.A.; Verevkin, S.P. Benchmark properties of biphenyl as liquid organic hydrogen carrier: Evaluation of thermochemical data with complementary experimental and computational methods. J. Chem. Thermodyn. 2018, 122, 1-12. [CrossRef]

57. Müller, K.; Stark, K.; Emel'yanenko, V.N.; Varfolomeev, M.A.; Zaitsau, D.H.; Shoifet, E.; Schick, C.; Verevkin, S.P.; Arlt, W. Liquid organic hydrogen carriers: Thermophysical and thermochemical studies of benzyl- and dibenzyl-toluene derivatives. Ind. Eng. Chem. Res. 2015, 54, 7967-7976. [CrossRef]

58. Stull, D.R.; Westrum, E.F.; Sinke, G.C. The Chemical Thermodynamics of Organic Compound; John Wiley \& Sons, Inc.: New York, NY, USA, 1969.

59. Sawada, H. Thermodynamics of polymerization. Polymer Rev. 1976, 3, 313-338.

60. Fujita, K.; Wada, T.; Shiraishi, T. Reversible Interconversion between 2,5-Dimethylpyrazine and 2,5-Dimethylpiperazine by Iridium-Catalyzed Hydrogenation/Dehydrogenation for Efficient Hydrogen Storage. Angew. Chem. Int. Ed. 2017, 56, 10886-10889. [CrossRef] [PubMed] 